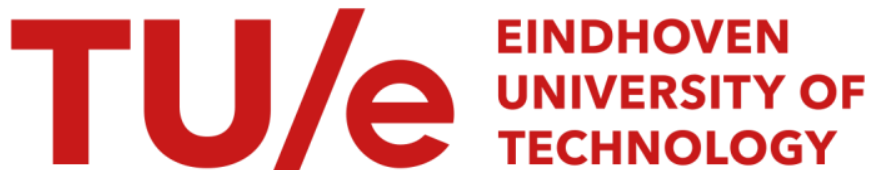

\section{Parametrization of a reactive force field for aluminum hydride}

\section{Citation for published version (APA):}

Ojwang, J. G. O., Santen, van, R. A., Kramer, G. J., Duin, van, A. C. T., \& Goddard III, W. A. (2009). Parametrization of a reactive force field for aluminum hydride. Journal of Chemical Physics, 131(4), 0445011/13. [044501]. https://doi.org/10.1063/1.3182853

DOI:

$10.1063 / 1.3182853$

Document status and date:

Published: 01/01/2009

\section{Document Version:}

Publisher's PDF, also known as Version of Record (includes final page, issue and volume numbers)

\section{Please check the document version of this publication:}

- A submitted manuscript is the version of the article upon submission and before peer-review. There can be important differences between the submitted version and the official published version of record. People interested in the research are advised to contact the author for the final version of the publication, or visit the DOI to the publisher's website.

- The final author version and the galley proof are versions of the publication after peer review.

- The final published version features the final layout of the paper including the volume, issue and page numbers.

Link to publication

\section{General rights}

Copyright and moral rights for the publications made accessible in the public portal are retained by the authors and/or other copyright owners and it is a condition of accessing publications that users recognise and abide by the legal requirements associated with these rights.

- Users may download and print one copy of any publication from the public portal for the purpose of private study or research.

- You may not further distribute the material or use it for any profit-making activity or commercial gain

- You may freely distribute the URL identifying the publication in the public portal.

If the publication is distributed under the terms of Article 25fa of the Dutch Copyright Act, indicated by the "Taverne" license above, please follow below link for the End User Agreement:

www.tue.nl/taverne

Take down policy

If you believe that this document breaches copyright please contact us at:

openaccess@tue.nl

providing details and we will investigate your claim. 


\title{
Parametrization of a reactive force field for aluminum hydride
}

\author{
J. G. O. Ojwang, ${ }^{1,2, a)}$ Rutger A. van Santen, ${ }^{1}$ Gert Jan Kramer, ${ }^{1}$ Adri C. T. van Duin, ${ }^{3}$ \\ and William A. Goddard III \\ ${ }^{1}$ Schuit Institute of Catalysis, Eindhoven University of Technology, Postbus 513, Den Dolech 2, \\ Eindhoven $5600 \mathrm{MB}$, The Netherlands \\ ${ }^{2}$ Geophysical Laboratory, Carnegie Institution of Washington, 5251 Broad Branch Rd. NW, \\ Washington D.C. 20012, USA \\ ${ }^{3}$ Department of Mechanical and Nuclear Engineering, Pennsylvania State University, University Park, \\ Pennsylvania 16802, USA \\ ${ }^{4}$ Materials and Process Simulation Center (MSC), California Institute of Technology, 1200 East California \\ Boulevard, Pasadena, California 91125, USA
}

(Received 2 April 2009; accepted 26 June 2009; published online 22 July 2009)

\begin{abstract}
A reactive force field, REAXFF, for aluminum hydride has been developed based on density functional theory (DFT) derived data. $\mathrm{REAXFF} \mathrm{AlH}_{3}$ is used to study the dynamics governing hydrogen desorption in $\mathrm{AlH}_{3}$. During the abstraction process of surface molecular hydrogen charge transfer is found to be well described by REAXFFAlH ${ }_{3}$. Results on heat of desorption versus cluster size show that there is a strong dependence of the heat of desorption on the particle size, which implies that nanostructuring enhances desorption process. In the gas phase, it was observed that small alane clusters agglomerated into a bigger cluster. After agglomeration molecular hydrogen was desorbed from the structure. This thermodynamically driven spontaneous agglomeration followed by desorption of molecular hydrogen provides a mechanism on how mobile alane clusters can facilitate the mass transport of aluminum atoms during the thermal decomposition of $\mathrm{NaAlH}_{4}$. (C) 2009 American Institute of Physics. [DOI: 10.1063/1.3182853]
\end{abstract}

\section{INTRODUCTION}

One of the major challenges in the quest for hydrogen storage solutions is the development of solid-state hydrogen storage media for vehicles. The United States' Department of Energy (DoE) has set a minimum target of $6 \mathrm{wt} \% \mathrm{H}_{2}$ for economically practical storage of hydrogen in a solid-state material by the year $2010 . \mathrm{AlH}_{3}$, which has about $10.1 \mathrm{wt} \%$ of $\mathrm{H}_{2}$ and a volumetric density of $0.148 \mathrm{~kg} \mathrm{H}_{2} / 1$, is quite attractive as a potential candidate for onboard hydrogen storage applications in proton exchange membrane fuel cells. $\mathrm{AlH}_{3}$ is a covalently bonded metastable binary hydride, with polymeric $\left(\mathrm{AlH}_{3}\right)_{n}$ forms. There are at least seven $\left(\alpha, \alpha^{\prime}, \beta\right.$, $\gamma, \delta, \varepsilon$, and $\zeta)$ known nonsolvated phases of $\mathrm{AlH}_{3}{ }^{1,2}$ Experimentally, under ambient conditions, the most stable phase of $\mathrm{AlH}_{3}$ is $\alpha-\mathrm{AlH}_{3}$, which has a trigonal/rhombohedral crystal structure (space group $R \overline{3} c$ ) with lattice parameters $a$ $=4.449 \AA$ and $c=11.804 \AA^{3} .^{3}$ The basic building unit of all the $\mathrm{AlH}_{3}$ polymorphs is the $\mathrm{AlH}_{6}$ octahedra and the $\alpha-\mathrm{AlH}_{3}$ polymorphic modification is the most densely packed. In 2005, Ke et al., ${ }^{4}$ using density functional theory (DFT), identified two structures of $\mathrm{AlH}_{3}$ (cubic $F d \overline{3} m$ and orthorhombic $\mathrm{Cmcm}$ ), which were theoretically calculated to be more stable than $\alpha-\mathrm{AlH}_{3}$. In 2006, the Institute for Energy Technology (IFE) experimentally solved the structure of orthorhombic $\alpha^{\prime}-\mathrm{AlH}_{3}$. In the same year, a joint collaboration of University of Hawaii (UH), IFE, and Brookhaven National Laboratory (BNL) synthesized and solved the structures of

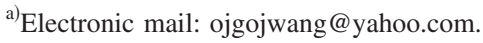

cubic $F d \overline{3} m\left(\beta-\mathrm{AlH}_{3}\right)$ and tetragonal Pnnm $\left(\gamma-\mathrm{AlH}_{3}\right)$ using organometallic methods. ${ }^{5}$ All the three structures were found to be less stable than $\alpha-\mathrm{AlH}_{3}$ at temperatures over $300 \mathrm{~K}$.

The metastable $\mathrm{AlH}_{3}$ does not release hydrogen under ambient conditions of temperature and pressure. Although all the known $\mathrm{AlH}_{3}$ phases are thermodynamically unstable with an equilibrium decomposition pressure in the range of kilobars at room temperature, they are usually metastable and slowly decompose at room temperature. The cause of this metastability is the encapsulation of the hydrogen in $\mathrm{AlH}_{3}$ by a layer of $\mathrm{Al}_{2} \mathrm{O}_{3}$ that surrounds the surface of the $\mathrm{AlH}_{3}$ particles. At atmospheric pressure and in the temperature range of 330-400 K, subject to its preparation history, the decomposition of $\mathrm{AlH}_{3}$ occurs in a single step as follows:

$$
\mathrm{AlH}_{3} \rightarrow \mathrm{Al}+\frac{3}{2} \mathrm{H}_{2}
$$

Thermodynamically, this reaction is not easily reversible. To rehydride $\mathrm{Al}$ back to $\mathrm{AlH}_{3}$ hydrogen gas pressures of over $2.5 \mathrm{GPa}$ are needed. ${ }^{6,7} \mathrm{AlH}_{3}$ has a low decomposition enthalpy of about $1.82 \mathrm{kcal} / \mathrm{mol} \mathrm{H}_{2},{ }^{8}$, which is $20 \%$ that of $\mathrm{NaAlH}_{4}{ }^{9}$ The decomposition rate of $\mathrm{AlH}_{3}$ can be tuned through nanostructuring (particle size reduction). ${ }^{5}$ However, the decomposition reaction of $\mathrm{AlH}_{3}$ is not reversible and therefore the desorbed hydrogen must be regenerated offboard. There are various ongoing research efforts to improve the sorption kinetics of $\mathrm{AlH}_{3}$. Sandrock et al. have shown that doping of $\mathrm{AlH}_{3}$ with small amounts of alkali metal hydrides ( $\mathrm{LiH}, \mathrm{NaH}$, and $\mathrm{KH}$ ) leads to accelerated $\mathrm{H}_{2}$ desorption rates at low temperatures. ${ }^{10,11}$ 
TABLE I. Bond energy and bond-order parameters. $D_{e}^{\sigma}$ is in kcal $/ \mathrm{mol}$.

\begin{tabular}{lccccc}
\hline \hline Bond & $D_{e}^{\sigma}$ & $P_{b e, 1}$ & $P_{b e, 2}$ & $P_{b 0,1}$ & $P_{b 0,2}$ \\
\hline Al-H & 93.4 & -0.6599 & 8.7138 & -0.08 & 6.978 \\
\hline \hline
\end{tabular}

In this work we have parametrized a reactive force field $\left(\right.$ REAXFFAlH ${ }_{3}$ ) for $\mathrm{AlH}_{3}$ with the objective of describing the $\mathrm{H}_{2}$ desorption process in $\mathrm{AlH}_{3}$. REAXFF has already been shown to be able to accurately predict the dynamical and reactive processes in hydrocarbons, ${ }^{12}$ silicon/silicon oxides, ${ }^{13}$ aluminum/aluminum oxides, ${ }^{14,15}$ nitramines, ${ }^{16}$ sodium hydride, ${ }^{17}$ and magnesium hydride. ${ }^{18}$ Herein, the details of the parametrizations of REAXFFAlH ${ }_{3}$, the diffusion mechanism of hydrogen atoms and hydrogen molecules in $\mathrm{AlH}_{3}$, the abstraction process of surface molecular $\mathrm{H}_{2}$ in $\mathrm{AlH}_{3}$ cluster, the possibility of phase transition between different polymorphic modifications during the heating process, and the role of alane clusters in the transportation of $\mathrm{Al}$ atoms are examined. In addition, interestingly, this paper shows that small alane molecules have to first of all agglomerate before desorption of molecular hydrogen can occur. This is very important in understanding the mass transport of aluminum atoms during the thermal decomposition process of $\mathrm{NaAlH}_{4} \cdot{ }^{19-21}$

This paper is organized as follows. Section II deals with force field parametrizations and the tests taken to ensure that the force field is well parametrized, Sec. III deals with the dynamics of hydrogen desorption in aluminum hydride clusters and the behavior of alanes on $\mathrm{Al}(111)$ surface, Sec. IV focuses on the abstraction process of molecular hydrogen from a cluster of $\mathrm{AlH}_{3}$, and Sec. V is devoted to the issue of trapped molecular hydrogen in the channels of a cluster of $\mathrm{AlH}_{3}$. We conclude in Sec. VI.

\section{FORCE FIELD PARAMETRIZATIONS}

REAXFFAlH ${ }_{3}$ has been parametrized in the same way as REAXFF $_{\mathrm{NaH}}$ (Ref. 17) and REAXFF ${ }_{\mathrm{MgH}} \cdot{ }^{18}$ The force field does not use fixed connectivity assignment between atoms but rather the bond-order formalism, which allows for bonds to be created and broken-up in line with the works of Tersoff ${ }^{22}$ and Brenner. ${ }^{23}$ REAXFF calculates nonbonded (van der Waals and Coulomb) interactions between all atoms (including 1-2, $1-3$, and 1-4 interactions) making it suitable for systems which have polar-covalent interactions. Implemented in REAXFF are polarizable charges that are calculated using electronegativity equalization method ${ }^{24}$ (EEM) and which provides a geometry dependent charge distribution.

The fitting data used in REAXFF were obtained from DFT using the efficient and accurate total-energy package, VASP (Vienna $a b$ initio simulation package). ${ }^{25}$ VASP implements a projector augmented plane-wave (PAW) approach. ${ }^{26}$ In deter-

TABLE II. Atom parameters $\left(p_{\mathrm{ov} / \mathrm{un}}\right.$ is in $\left.\mathrm{kcal} / \mathrm{mol}\right)$.

\begin{tabular}{lcccc}
\hline \hline Atom & $p_{\text {ov/un }}$ & $\lambda_{11}$ & $p_{v, 5}$ & $p_{v, 6}$ \\
\hline $\mathrm{Al}$ & -23.18 & 2.53 & 8.0 & 2.5791 \\
$\mathrm{H}$ & -15.76 & 2.15 & 1.0 & 2.8793 \\
\hline \hline
\end{tabular}

mining the relaxed geometries of the structures considered in this work, a plane-wave cutoff of $600 \mathrm{eV}(1 \mathrm{eV}$ $=23.06 \mathrm{kcal} / \mathrm{mol}$ ) was used. A convergence of $10^{-6} \mathrm{eV} /$ atom was placed as a criterion on the selfconsistent convergence of the total energy. The ions involved are steadily relaxed toward equilibrium until the HellmanFeynman forces are minimized to less than $0.02 \mathrm{eV} / \AA$ using conjugate gradient algorithm during all relaxation runs. A further local optimization was done on the already relaxed structure using quasi-Newton algorithm until the HellmanFeynman forces on the ions were less than $0.005 \mathrm{eV} / \mathrm{A}$. To represent electronic-correlation effects for a particular ionic configuration, the calculations used the generalized gradient approximation of Perdew and Wang (GGA-PW91). ${ }^{27-29}$ For cluster calculations, a cubic supercell of side of $20 \AA$ was used and the Brillouin zone was sampled at the $\Gamma$ point. For all the $\mathrm{AlH}_{3}$ condensed phases, Brillouin zone integrations were performed using $4 \times 4 \times 4 \quad k$-points as per the Monkhorst-Pack grid scheme. ${ }^{30}$ The reference configurations for valence electrons used were $\mathrm{Al}\left(3 s^{2} 3 p^{1}\right)$ and $\mathrm{H}\left(1 s^{1}\right)$.

To parametrize REAXFF energy expressions, a fitting was done to a training set containing the DFT derived equations of state (EoSs) of pure $\mathrm{Al}$ and $\mathrm{AlH}_{3}$ condensed phases, reaction energies, and bond dissociation profiles on small finite clusters. The bond and atom parameters for REAXFF energy functions (Tables I and II) were determined from $\mathrm{Al}-\mathrm{Al}$ and $\mathrm{Al}-\mathrm{H}$ bonds in small $\mathrm{AlH}_{3}$ clusters such as $\mathrm{AlH}_{3}, \mathrm{Al}_{2} \mathrm{H}_{6}$, $\mathrm{Al}_{3} \mathrm{H}_{9}, \mathrm{Al}_{4} \mathrm{H}_{12}, \mathrm{Al}_{5} \mathrm{H}_{15}, \mathrm{Al}_{6} \mathrm{H}_{18}, \mathrm{Al}_{7} \mathrm{H}_{21}$, and $\mathrm{Al}_{8} \mathrm{H}_{24}$ and from the EoSs and cohesive energies of Al-metal and $\mathrm{AlH}_{3}$ condensed phases. The symbols of the parameters in Tables I-IV are shown in Refs. 13 and 16.

Table III shows the EEM parameters (EEM hardness $\eta$, EEM electronegativity $\chi$, and EEM-shielding parameter $\gamma$ ). These parameters were optimized to fit Mulliken charge distributions of small representative structures $\left(\mathrm{AlH}_{3}, \mathrm{Al}_{2} \mathrm{H}_{6}\right.$, $\mathrm{Al}_{3} \mathrm{H}_{9}$, and $\mathrm{Al}_{4} \mathrm{H}_{12}$ ) obtained from DFT calculations. REAXFF successfully reproduces charge transfer for all the clusters considered. The partial charges fitted into the training set were obtained by performing a Mulliken charge distribution analysis in an all electron calculation in CRYSTAL06. ${ }^{31,32}$ CRYSTAL06 implements a localized basis set approach. The radical factors in the all electron basis set are expressed as a linear combination of Gaussian-type functions of the electron-nucleus distance according to $85(s) 11(s p) G$ and $5(s) 11(s p) 1(p) G$ contractions for $\mathrm{Al}$ and $\mathrm{H}$, respectively. ${ }^{32}$

TABLE III. Coulomb parameters.

\begin{tabular}{lccc}
\hline \hline & $\begin{array}{c}\eta \\
(\mathrm{kcal} / \mathrm{mol})\end{array}$ & $\begin{array}{c}\chi \\
(\mathrm{kcal} / \mathrm{mol})\end{array}$ & $\begin{array}{c}\gamma \\
(\AA)\end{array}$ \\
\hline Atom & 4.9 & 1.8921 & 0.6191 \\
$\mathrm{Al}$ & 6.5 & 4.1882 & 0.7358 \\
$\mathrm{H}$ & & & \\
\hline \hline
\end{tabular}


TABLE IV. Valence angle parameters.

\begin{tabular}{lrrrcccr}
\hline \hline Angle & $\Theta \Theta_{0,0}$ & \multicolumn{1}{c}{$k_{a}$} & $k_{b}$ & $p_{v, 1}$ & $p_{v, 2}$ & $p_{\text {pen }}$ & $p_{v, 4}$ \\
\hline H-Al-Al & 66.95 & 39.1233 & 0.1935 & 0 & 1.0 & 0 & 2.99 \\
H-Al-Al & 180.00 & -26.6261 & 5.3467 & 0 & 1.0 & 0 & 1.01 \\
H-Al-H & 70.85 & 3.4517 & 8.8151 & 0 & 3.0 & 0 & 2.40 \\
Al-H-Al & $0.00^{\mathrm{a}}$ & 36.0088 & 0.0603 & 0 & 3.0 & 0 & 1.01 \\
\hline \hline
\end{tabular}

${ }^{\mathrm{a}}$ The value leads to an equilibrium angle of $180-0=180^{\circ}$ for the single bond $\mathrm{Al}-\mathrm{H}-\mathrm{Al}$ valence angle.

To ensure high numerical accuracy the truncation tolerance for the numerical evaluation of bielectronic integrals (both the Coulomb and the Hartree-Fock exchange series) were set at $10^{-8}, 10^{-8}, 10^{-8}, 10^{-8}$, and $10^{-16} .^{32}$ All the units are in a.u. (1 a.u. $=627.51 \mathrm{kcal} / \mathrm{mol})$.

Table IV shows the optimized valence angle parameters for $\mathrm{H}-\mathrm{Al}-\mathrm{Al}$ and $\mathrm{H}-\mathrm{Al}-\mathrm{H}$ angles. To obtain these quantities, the clusters are first fully optimized in DFT calculations. This is followed by doing single point calculations in which the valence angles are modified while other parameters are fixed. The first line reflects a normal $\mathrm{H}-\mathrm{Al}-\mathrm{Al}$ angle interaction, with an equilibrium angle of $113.05^{\circ}$ and force constants of 39.1233 and $0.1935 \mathrm{kcal}$. The valence angle with a negative force constant ( $\mathrm{H}-\mathrm{Al}-\mathrm{Al}),-26.6261 \mathrm{kcal}$, aims to destabilize the case where the hydrogen atom is exactly in between the $\mathrm{Al}$ atoms (i.e., $\mathrm{H}-\mathrm{Al}-\mathrm{Al}$ angle is zero degrees). This is effectively an inverted angle function, with a maximum at $\mathrm{H}-\mathrm{Al}-\mathrm{Al}$ equals zero degrees and falling off to zero for different values of this angle.

\section{A. Bond dissociation, angle bending, and binding energies}

Figure 1(a) shows the bond dissociation curve of $\mathrm{AlH}_{3}$, while Fig. 1(b) shows the angle bending-energy curve of the $\mathrm{AlH}_{3}$ molecule used to optimize the valence angle parameter of REAXFFAlH $\mathrm{H}_{3}$. These DFT curves were used to optimize the bond energy in the reactive potential. The dissociation curves were constructed from the equilibrium geometry using single point calculations by changing the bond length. REAXFF gives an equilibrium bond length of $1.6 \AA$, which is in excellent agreement with DFT value of $1.59 \AA$. The energies were computed with reference to the equilibrium bond length's energy. To optimize the valence angle parameter the geometry of the $\mathrm{AlH}_{3}$ molecule was minimized for various fixed values, viz $120^{\circ}, 115^{\circ}, 110^{\circ}, \ldots, 65^{\circ}, 60^{\circ}$. REAXFF predicts that the $\mathrm{H}-\mathrm{Al}-\mathrm{H}$ equilibrium angle is $120^{\circ}$. This is in excellent agreement with DFT. For smaller angles, DFT gives larger energy barriers than REAXFF due to electronelectron repulsion inherent in the former. For instance, at $60^{\circ}$ the $\mathrm{AlH}_{3}$ is destabilized by $44.4 \mathrm{kcal} / \mathrm{mol}$ in DFT, whereas REAXFF, which does not care about electrons, gives a destabilization energy of $11.66 \mathrm{kcal} / \mathrm{mol}$.

Table V shows the DFT values versus REAXFF values of adsorption energies of hydrogen on $\mathrm{Al}(111)$ surface. The adsorption energy $E_{\text {ads }}$ is defined as $E_{\text {ads }}=\left[E_{(\mathrm{S} / \mathrm{H})}-E_{\mathrm{S}}\right.$ $\left.-n E_{(\mathrm{H})}\right] / n$, where $E_{(\mathrm{S} / \mathrm{H})}$ is the total energy of hydrogenadsorbed aluminum slab, $E_{\mathrm{S}}$ is the total energy of aluminum slab, $E_{\mathrm{H}}$ is the total energy of hydrogen atom $(-25.79 \mathrm{kcal} /$ $\mathrm{mol}$ ), and $n$ stands for the number of adsorbed hydrogen atoms. In the context of this definition, $E_{\text {ads }}<0$ corresponds to exothermic adsorption. To calculate $E_{\mathrm{H}}$, two hydrogen atoms were placed $12 \AA$ apart in a cubic box of side of $20 \AA$. The Brillouin zone was sampled at the gamma point. The total energy of the hydrogen atom was then taken as half the calculated total energy. The Al surface was modeled by a repeated slab of five layers, giving a slab thickness of $9.6 \AA$. A vacuum equivalent to a slab with five layers of aluminum atoms was imposed in the $z$-direction to separate the slab from its periodic images. $\mathrm{H}$ is adsorbed on one side of the slab only. The top two layers plus the $\mathrm{H}$ atom are relaxed while the bottom three layers are fixed at their bulk positions. The Brillouin zone was sampled using a well converged 9 $\times 9 \times 1 k$-points.

REAXFF gives decent adsorption energies in comparison to DFT predictions (Table V). From DFT calculations, atomic hydrogen preferably adsorbs on the fcc site. This is consistent with the work of Stumpf, ${ }^{33}$ who showed that $\mathrm{H}$ preferably adsorbs on the fcc site with an exothermic adsorption energy from -45.58 to $-45.89 \mathrm{kcal} / \mathrm{mol}$ (depending on the coverage). This value can be slightly higher or lower depending on the exchange-correlation functional (LDA, PBE, or PW91) used. In agreement with Stumpf, we calculated the fcc adsorption energy to be $-47.63 \mathrm{kcal} / \mathrm{mol}$. From REAXFF, the adsorption energies for bridge, hcp, and top sites
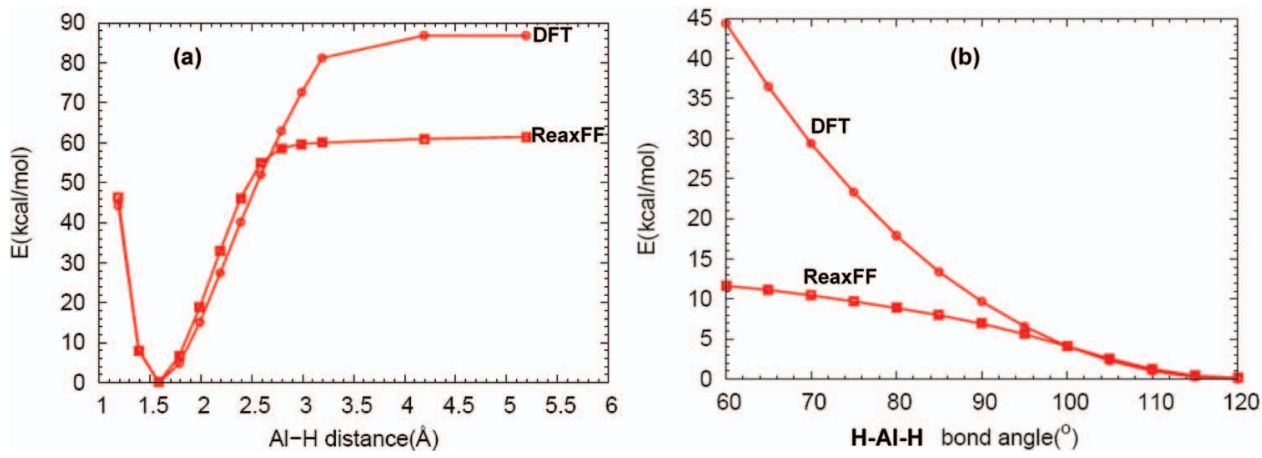

FIG. 1. (a) Bond dissociation profile of $\mathrm{AlH}_{3}$. REAXFF gives an equilibrium bond length of $1.6 \AA$ A This is in excellent agreement with DFT value of 1.59 Å. (b) $\mathrm{H}-\mathrm{Al}-\mathrm{H}$ angle bend in $\mathrm{AlH}_{3}$ molecule. The energies are computed with reference to the equilibrium angle energy. 
TABLE V. Adsorption energies of hydrogen atoms on the high symmetry sites on $\mathrm{Al}(111)$ surface. The energies are in $\mathrm{kcal} / \mathrm{mol}$ per $\mathrm{H}$.

\begin{tabular}{lcc}
\hline \hline Site & DFT & REAXFF \\
\hline hcp & -44.80 & -47.80 \\
fcc & -47.63 & -49.24 \\
Top & -45.87 & -47.14 \\
Bridge & -47.37 & -48.93 \\
\hline \hline
\end{tabular}

are $-47.37,-44.80$, and $-45.87 \mathrm{kcal} / \mathrm{mol}$, respectively.

For $\mathrm{Al}(111) \mathrm{hcp}$ site DFT gives a value of $-44.8 \mathrm{kcal} /$ mol per $\mathrm{H}$, while REAXFF gives $-47.8 \mathrm{kcal} / \mathrm{mol}$. For $\mathrm{Al}(111)$ fcc site DFT predicts the adsorption energy to be -47.63 $\mathrm{kcal} / \mathrm{mol}$, while REAXFF gives $-49.24 \mathrm{kcal} / \mathrm{mol}$. For the $\mathrm{Al}(111)$ top site REAXFF predicts the adsorption energy to be $-47.14 \mathrm{kcal} / \mathrm{mol}$, which is in good agreement with the DFT value of $-45.87 \mathrm{kcal} / \mathrm{mol}$. The DFT calculated energy barrier for $\mathrm{H}$ hopping from the bridge to the fcc site is 2.07 $\mathrm{kcal} / \mathrm{mol}$. REAXFF gives a migration energy barrier of 2.7 $\mathrm{kcal} / \mathrm{mol}$, which is in excellent agreement with the DFT value. These values are in good agreement with those of Hjelmberg who determined the diffusion energy barrier of $\mathrm{H}$ from the bridge to threefold site to be in the range of 2.3-4.6 $\mathrm{kcal} / \mathrm{mol}^{34}$

Since the goal of this force field was to study the interaction of alane clusters in the gas phase and on aluminum surface, we also considered the binding energies of alane molecules on $\mathrm{Al}(111)$ surface. These energies for various alane cluster models are tabulated in Table VI. As can be seen in Table VI REAXFF gives values that are quite close to DFT values.

That said, there is an increasing interest in studying small clusters of aluminum hydride since nanostructuring might be the key to hydrogen storage in $\mathrm{AlH}_{3}$ system. During the thermal decomposition process of large systems of aluminum hydride, it is possible that the release of hydrogen and subsequent formation of aluminum clusters occurs in tandem with cluster fragmentation. ${ }^{17}$ Herein, we make a comparison between DFT's binding energies and REAXFF binding energies for $\mathrm{AlH}_{3}, \mathrm{Al}_{2} \mathrm{H}_{6}, \mathrm{Al}_{3} \mathrm{H}_{9}, \mathrm{Al}_{4} \mathrm{H}_{12}$, and $\mathrm{Al}_{5} \mathrm{H}_{15}$ clusters. These small clusters are shown in Fig. 2.

Kawamura et al. ${ }^{35}$ have given an extensive study of small $\mathrm{AlH}_{3}$ clusters and have shown that the energetics are very close for singly bridged cyclic, doubly bridged cyclic, and linear clusters. In general, the singly bridged structures are more favored over the doubly bridged structures. However, Kawamura et al. also found out that in some instances, due to exchange-correlation effects, the doubly bridged structures are preferred to singly bridged structures. In RE-

TABLE VI. Binding energies of $\mathrm{AlH}_{3}, \mathrm{Al}_{2} \mathrm{H}_{6}$, and $\mathrm{Al}_{3} \mathrm{H}_{9}$ on $\mathrm{Al}(111)$ surface.

\begin{tabular}{lcc}
\hline \hline Cluster & $\begin{array}{c}\text { DFT } \\
(\mathrm{kcal} / \mathrm{mol})\end{array}$ & $\begin{array}{c}\text { REAXFF } \\
(\mathrm{kcal} / \mathrm{mol})\end{array}$ \\
\hline $\mathrm{AlH}_{3}$ on terrace (horizontal) & -20.98 & -15.18 \\
$\mathrm{Al}_{2} \mathrm{H}_{6}$ on terrace & -49.81 & 46.95 \\
$\mathrm{Al}_{3} \mathrm{H}$ 9 on terrace & -51.65 & -44.39 \\
\hline \hline
\end{tabular}

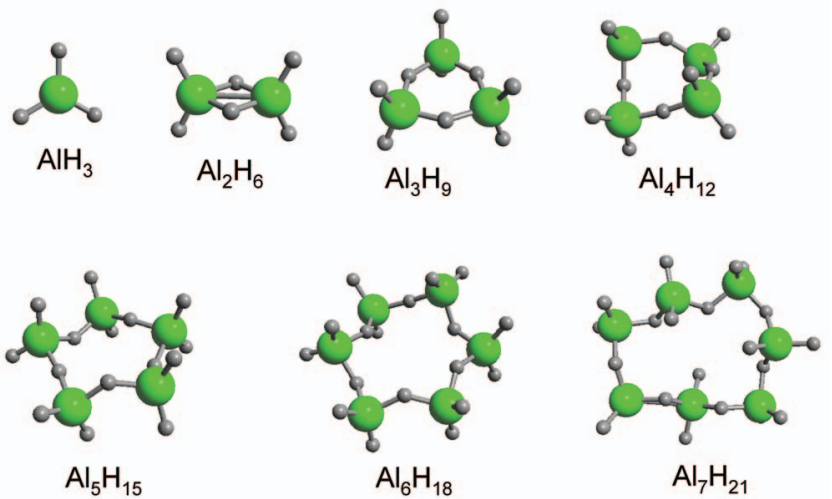

FIG. 2. Small representative $\left[\mathrm{AlH}_{3}\right]_{n}, n=1-7$, clusters used in the training set of REAXFF.

AXFF computations, it was seen that for $\mathrm{Al}_{n} \mathrm{H}_{3 n}(n \geq 4)$ the doubly bridged structures are preferred while the singly bridged structures are unstable. This can be understood from the fact that the more the interconnectivity of the Al-H bonds the stronger the bonding. Doubly bridged structures have more bonds and therefore bound to be more stable than singly bridged structures. Table VII shows the binding energies of various $\left(\mathrm{AlH}_{3}\right)_{n}$ clusters considered in this work. Here, the binding energy is defined as:

$$
\mathrm{BE}=-\left[E\left(\mathrm{Al}_{n} \mathrm{H}_{2 m}\right)-E\left(\mathrm{Al}_{\mathrm{fcc}}\right)-m E\left(\mathrm{H}_{2}\right)\right] / m,
$$

where $E(\mathrm{P})$ is the total energy of particle $\mathrm{P}$ in the ground state. For molecular hydrogen, in DFT, $E_{\text {tot }}=$ $-156.87 \mathrm{kcal} / \mathrm{mol}$. The total energy of molecular hydrogen was used because in REAXFF the total energy is computed with reference to the isolated atomic species. The DFT values are consistent with the works of Kawamura et al. However, Kawamura et al. used the total energy of atomic hydrogen instead of that of molecular hydrogen. Therefore, in Table VIII we make a comparison between DFT values and the work of Kawamura et al. ${ }^{35}$ using the total energy of atomic hydrogen, $E_{\mathrm{tot}}=-25.79 \mathrm{kcal} / \mathrm{mol}$. There is an excellent match between our calculated DFT values and those from the work of Kawamura et al., which was done at the LCAO+GGA level of theory. It can be seen in the table that there is a slow decrease in binding energy per hydrogen of these clusters with increasing cluster size. This is contrary to the expectation that the binding energy per hydrogen should increase concomitantly with increase in cluster size. The decrease in the binding energy can be attributed to the fact that as the cluster size increases so does the free energy of pure aluminum clusters, which raises the cost of fragmenting the

TABLE VII. Binding energies BEs (in $\mathrm{kcal} / \mathrm{mol} \mathrm{H}_{2}$ ) of small $\mathrm{AlH}_{3}$ clusters used in the training set.

\begin{tabular}{lcc}
\hline \hline Cluster & DFT & REAXFF \\
\hline $\mathrm{AlH}_{3}$ & 30.77 & 32.51 \\
$\mathrm{Al}_{2} \mathrm{H}_{6}$ & 22.60 & 28.66 \\
$\mathrm{Al}_{3} \mathrm{H}_{9}$ & 29.72 & 30.13 \\
$\mathrm{Al}_{4} \mathrm{H}_{12}$ & 39.33 & 34.50 \\
$\mathrm{Al}_{5} \mathrm{H}_{15}$ & 42.88 & 38.80 \\
\hline
\end{tabular}


TABLE VIII. Comparison between DFT and binding energies BEs of Kawamura et al. (in kcal/mol H) of small $\mathrm{AlH}_{3}$ clusters.

\begin{tabular}{lcc}
\hline \hline Cluster & DFT & Ref. 35 \\
\hline $\mathrm{AlH}_{3}$ & 68.79 & 67.50 \\
$\mathrm{Al}_{2} \mathrm{H}_{6}$ & 70.01 & 70.29 \\
$\mathrm{Al}_{3} \mathrm{H}_{9}$ & 64.98 & 65.19 \\
$\mathrm{Al}_{4} \mathrm{H}_{12}$ & 63.53 & 62.70 \\
$\mathrm{Al}_{5} \mathrm{H}_{15}$ & 61.52 & 60.65 \\
$\mathrm{Al}_{6} \mathrm{H}_{18}$ & 60.21 & 59.22 \\
$\mathrm{Al}_{7} \mathrm{H}_{21}$ & 58.60 & 57.63 \\
$\mathrm{Al}_{8} \mathrm{H}_{24}$ & 58.50 & 58.60 \\
\hline \hline
\end{tabular}

aluminum clusters to accommodate hydrogen atoms.

In the condensed state, for each an every phase of $\mathrm{AlH}_{3}$ $\left(\alpha, \alpha^{\prime}, \beta\right.$, and $\left.\gamma\right)$ polymorphic modifications considered in this work, the DFT energies were computed for a broad range of volume describing both expansion and compression. Figure 3 shows the crystal structure of the four polymorphs of $\mathrm{AlH}_{3}\left(\alpha, \alpha^{\prime}, \beta, \gamma\right)$ considered in this work. All the $\mathrm{AlH}_{3}$ polymorphs are made up of three dimensional networks of $\mathrm{AlH}_{6}$ units. $\alpha-\mathrm{AlH}_{3}$ crystallizes in the trigonal $R \overline{3} c$ space group, $\beta$ - $\mathrm{AlH}_{3}$ crystallizes in the cubic $F d \overline{3} m$ space group, $\alpha^{\prime}-\mathrm{AlH}_{3}$ crystallizes in the $\mathrm{Cmcm}$ space group, and $\gamma-\mathrm{AlH}_{3}$ crystallizes in the orthorhombic Pnnm space group.

The issue of the relative stability of $\mathrm{AlH}_{3}$ polymorphic modifications is quite interesting. Experimentally, $\alpha-\mathrm{AlH}_{3}$ is the most stable polymorph for temperatures greater than or equal to $300 \mathrm{~K}^{3}{ }^{3}$ Theoretically, Ke et al. ${ }^{4}$ using DFT, found $\beta$ - $\mathrm{AlH}_{3}$ polymorphic modification of $\mathrm{AlH}_{3}$ to be the structure with the lowest energy. It is possible that at $0 \mathrm{~K}$ the $\beta$-phase is indeed more stable than the $\alpha$-phase as found by $\operatorname{Ke}$ et al. On the other hand, the relative energy differences between these two phase are in the order of $1 \mathrm{kcal} / \mathrm{mol}$. It might be that it is difficult for DFT to resolve this small energy difference. We found that indeed the cubic $\beta-\mathrm{AlH}_{3}$ has the lowest energy. However, this result seems to be an artifact of the pseudopotential (PP) used. For the PAW PPs the $\beta-\mathrm{AlH}_{3}$

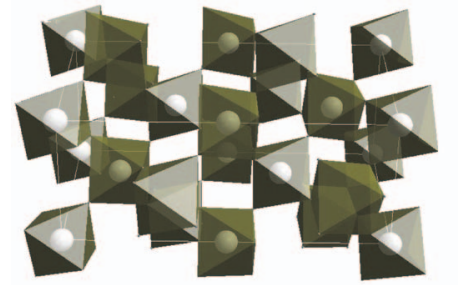
$\alpha \quad(110)$

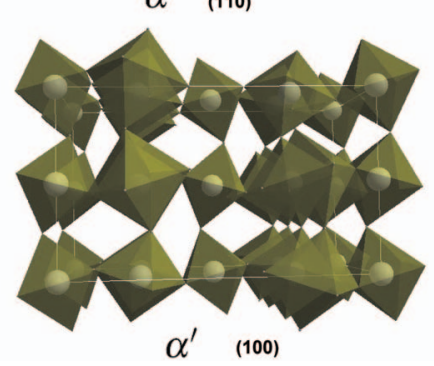

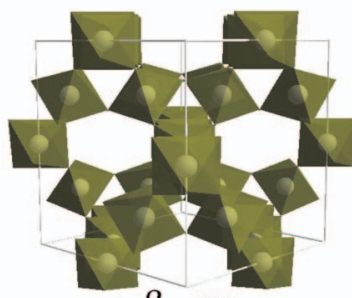

$\beta$ (111)

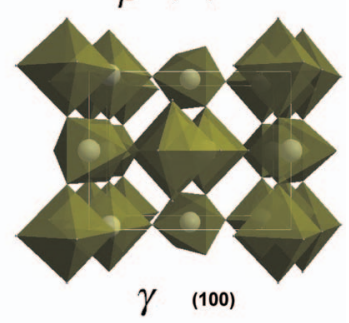

FIG. 3. The various polymorphic modifications of $\mathrm{AlH}_{3}$ illustrated by the connection of the $\mathrm{AlH}_{6}$ octahedra and channels through the polymorphs.
TABLE IX. Relative stability of three $\mathrm{AlH}_{3}$ phases with respect to the $R \overline{3} c$ phase using the PAW and US-PP and REAXFF. The units are in $\mathrm{kcal} / \mathrm{mol}$.

\begin{tabular}{lccc}
\hline \hline Phase & PAW & US-PP & REAXFF \\
\hline$R \overline{3} c$ & 0 & 0 & 0 \\
$F d \overline{3} m$ & -0.76 & -0.76 & -0.02 \\
$C m c m$ & -0.39 & -1.04 & +0.38 \\
Pnnm & +0.53 & +0.51 & +2.56 \\
\hline \hline
\end{tabular}

phase has the lowest energy, whereas for ultrasoft (US) PP $\alpha^{\prime}-\mathrm{AlH}_{3}$ phase has the lowest energy, see Table IX. In both cases, however, the relative energy differences between $\alpha$, $\alpha^{\prime}$, and $\beta$ phases are less than $1 \mathrm{kcal} / \mathrm{mol}$. This implies that it should be possible for these phases to transform into one another at certain temperatures and pressures. In particular, since the $\beta$ phase has more open channels, it can transform to the $\alpha$ phase during the desorption of molecular hydrogen but only if the $\alpha$ phase is more stable. We did not include the ZPE corrections. In the work of Ke et al., zero point energy (ZPE) corrections were included.

Figure 4 shows the EoS for the $R \overline{3} c\left(\alpha-\mathrm{AlH}_{3}\right), F d \overline{3} m$ $\left(\beta-\mathrm{AlH}_{3}\right)$, Pnnm $\left(\gamma-\mathrm{AlH}_{3}\right)$, and $\mathrm{Cmcm}\left(\alpha^{\prime}-\mathrm{AlH}_{3}\right)$ phases of $\mathrm{AlH}_{3}$. REAXFF correctly describes the EoS of the four phases of $\mathrm{AlH}_{3}$ and excellently estimates their relative phase stability vis-á-vis the DFT's predictions. For instance, DFT (PAW) predicts that $\beta-\mathrm{AlH}_{3}$ is more stable than $\gamma-\mathrm{AlH}_{3}$ by 0.76 $\mathrm{kcal} / \mathrm{mol} \mathrm{H}_{2}$, whereas REAXFF gives a value of $0.02 \mathrm{kcal} / \mathrm{mol}$ $\mathrm{H}_{2}$. The experimental heat of formation, for the condensed phase, of $\mathrm{AlH}_{3}$ range from $-2.37 \pm 0.1 \mathrm{kcal} / \mathrm{mol} \mathrm{H}_{2}$ (Ref. 2) to $-2.72 \pm 0.2 \mathrm{kcal} / \mathrm{mol} \mathrm{H}_{2}{ }^{8}$, while the calculated values are in the range from $-1.66 \mathrm{kcal} / \mathrm{mol} \mathrm{H}_{2}$ (Ref. 36) to -2.95 $\mathrm{kcal} / \mathrm{mol} \mathrm{H}_{2}{ }^{4}$ For $\alpha-\mathrm{AlH}_{3}$ phase, both DFT and REAXFF give bulk values that are consistent with the calculated values, with DFT giving a value of $-2.36 \mathrm{kcal} / \mathrm{mol} \mathrm{H}_{2}$ and REAXFF giving $-3.01 \mathrm{kcal} / \mathrm{mol} \mathrm{H}_{2}$. These values were calculated by comparing to $\mathrm{Al}(\mathrm{fcc})$ at its most stable volume and $1.5 \mathrm{H}_{2}$ (gas).

During the thermal desorption process there might be phase transformations/crystal modifications or conforma-

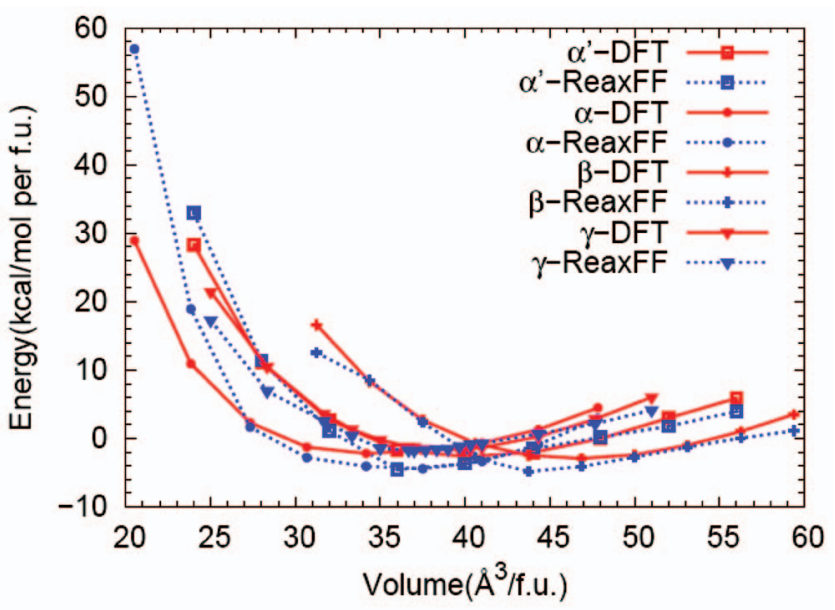

FIG. 4. EoSs for $\mathrm{AlH}_{3}$ phases (DFT values are drawn using straight lines while those for REAXFF are drawn using dotted lines). 


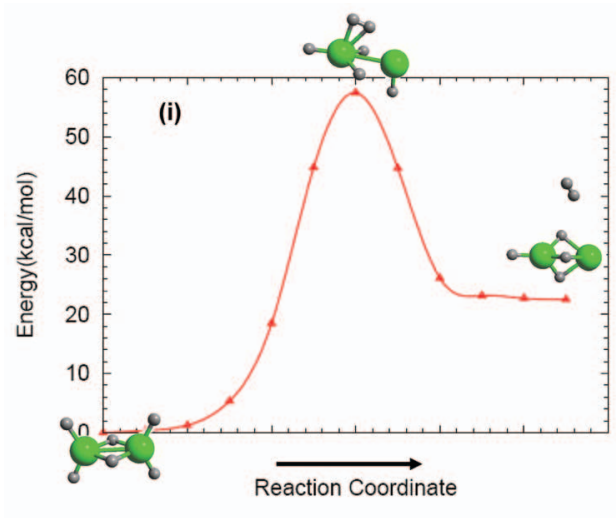

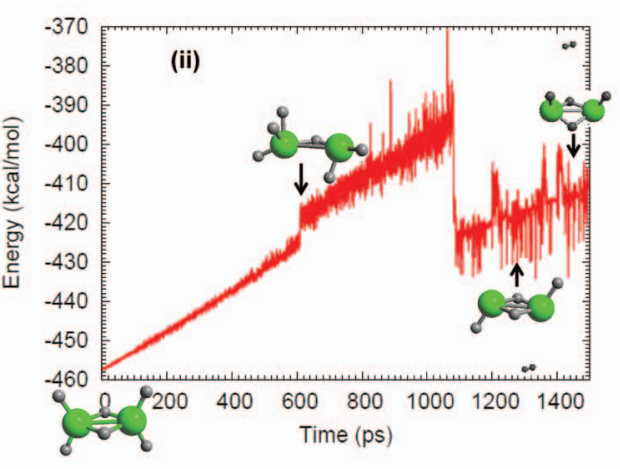

FIG. 5. (i) Dissociation profile of $\mathrm{Al}_{2} \mathrm{H}_{6}$ as calculated by DFT using nudged elastic band method. (ii) The energy profile during a MD simulation of a heating run of $\mathrm{Al}_{2} \mathrm{H}_{6}$. The temperature was ramped up at a rate of $0.00025 \mathrm{~K}$ /iteration tional changes in both $\mathrm{Al}$ and $\mathrm{AlH}_{3}$ systems. Graetz et al. ${ }^{2}$ showed that transitions between $\alpha, \beta$, and $\gamma$ phases are exothermic and likely to occur spontaneously even at room temperature. Further, Grove et al. ${ }^{37}$ showed that in the case of deuterated $\mathrm{Al}$, there is a phase transformation of both $\beta-\mathrm{AlD}_{3}$ and $\gamma-\mathrm{AlD}_{3}$ to $\alpha-\mathrm{AlD}_{3}$ starting at 353 and $363 \mathrm{~K}$, respectively. Maehlen et al. ${ }^{38}$ observed a phase transformation of $\gamma-\mathrm{AlH}_{3}$ to $\alpha-\mathrm{AlH}_{3}$ during the decomposition process of the former. There have been claims that such transitions are expected and, in fact, are indicative that the system transforms to a less stable structure. However, it should be noted that the formation of the various polymorphs of $\mathrm{AlH}_{3}$ depends on their preparation history. Second, a clear sign that the resulting structure is more stable than the starting structure is to do the reverse process, i.e., reduce the temperature to $0 \mathrm{~K}$. If indeed the structure is more stable it should not transform back to the starting $(\beta)$ phase. It is important to emphasize that the $\alpha-\mathrm{AlH}_{3}$ is considered stable for temperatures $\geq 300 \mathrm{~K}$. Therefore, it is possible that for temperatures below $300 \mathrm{~K}$ the $\beta$ phase can be more stable than the $\alpha$ phase.

Since REAXFF was parametrized using DFT values, it has that the $\beta$ phase is the most stable phase. To reflect the experimental observations on relative stabilities of the four aluminum hydride phases (especially the experimentally observed phase transition of $\beta$ - to $\alpha$-phase during heating process), we modified the force field so as to make the $\alpha$-phase the most stable. In the work of Graetz et al. the heats of formation of the three polymorphic modifications are as follows: $\alpha-\mathrm{AlH}_{3}\left(-2.366 \mathrm{kcal} / \mathrm{mol} \mathrm{H}_{2}\right), \beta-\mathrm{AlH}_{3}$ $\left(-1.912 \mathrm{kcal} / \mathrm{mol} \mathrm{H} \mathrm{H}_{2}\right)$, and $\gamma-\mathrm{AlH}_{3}\left(-1.617 \mathrm{kcal} / \mathrm{mol} \mathrm{H}_{2}\right)$. We modified REAXFF by these values so as to reflect the experimental results. For the modified force field, the heats of formation of the three polymorphic modifications are as follows: $\alpha-\mathrm{AlH}_{3}\left(-4.32 \mathrm{kcal} / \mathrm{mol} \mathrm{H}_{2}\right), \beta-\mathrm{AlH}_{3}(-1.40 \mathrm{kcal} /$ $\left.\mathrm{mol} \mathrm{H}_{2}\right)$, and $\gamma-\mathrm{AlH}_{3}\left(-0.17 \mathrm{kcal} / \mathrm{mol} \mathrm{H}_{2}\right)$. These values are in good agreement with the experimental values of Graetz et $a .^{2}$

\section{DYNAMICS OF HYDROGEN DESORPTION}

An important part of force field parametrization is to get the right reaction dynamics during the thermal decomposition of a cluster (or bulk) of aluminum hydride. Therefore, to ascertain that the force field reproduces the right thermal decomposition dynamics, we heated up a representative aluminum hydride cluster $\left(\mathrm{Al}_{2} \mathrm{H}_{6}\right) \cdot \mathrm{Al}_{2} \mathrm{H}_{6}$ decomposes endothermically as follows:

$$
\mathrm{Al}_{2} \mathrm{H}_{6} \rightarrow \mathrm{Al}_{2} \mathrm{H}_{4}+\mathrm{H}_{2}, \quad \Delta H_{r}=22.95 \mathrm{kcal} / \mathrm{mol} \text {. }
$$

The transition state and the minimum energy path (MEP) for the process in Eq. (3) was calculated in VASP (DFT) using NEB. ${ }^{39}$ This is shown in Fig. 5(i). In the NEB simulation it was ascertained that both end points were stable manifolds by performing frequency analysis. To get an accurate identification of the saddle point the climbing image flag was turned on. ${ }^{40}$ This has the effect of driving up to the saddle point the image with the highest energy. This permits an accurate determination of the transition state. To compute the activation energy barrier, the image at the top of the MEP was further locally optimized in VASP using quasi-Newton algorithm. The barrier was calculated to be $51 \mathrm{kcal} / \mathrm{mol}$. In REAXFF the barrier was calculated to be $50 \mathrm{kcal} / \mathrm{mol}$. In general, the dissociation process is endothermic but since the transition state is at a higher energy than the end point, then a fall in potential energy during the stage where molecular hydrogen is released is expected, which indicates that this portion of the reaction is an exothermic process. This is also reflected in Fig. 5(ii), which shows the energy profile during a molecular dynamics (MD) simulation of a heating run of $\mathrm{Al}_{2} \mathrm{H}_{6}$ at $0.00025 \mathrm{~K}$ /iteration. In the MD simulation, velocity Verlet algorithm was used and the temperature was increased linearly by velocity scaling. The dynamics of hydrogen desorption in the two instances are similar. In Fig. 5(ii) there is a slight rise in energy at about 600 ps. This energy rise occurs due to the distortion of the $\mathrm{Al}_{2} \mathrm{H}_{6}$ structure. Also shown in Fig. 5(ii), after fragmentation of $\mathrm{Al}_{2} \mathrm{H}_{6}$ into $\mathrm{Al}_{2} \mathrm{H}_{4}$ and $\mathrm{H}_{2}$, are the various geometrical modifications of the resultant $\mathrm{Al}_{2} \mathrm{H}_{4}$ during the heating process. The most important point to note in Fig. 5(ii) is that like in DFT, the desorption of molecular hydrogen in MD simulation is accompanied by a fall in the potential energy just after the transition state. This gives confidence that the force field reproduces the right desorption dynamics in comparison to DFT.

Table $\mathrm{X}$ shows the approximate temperature at which molecular hydrogen was desorbed (cluster dissociation) from various $\mathrm{Al}_{n} \mathrm{H}_{3 n}$ clusters. These temperatures are an approximation. In reality, the true fragmentation/desorption temperatures might be much lower, subject to long equilibration times, which is beyond the timescale of our simulation. The 
TABLE X. The temperature at which molecular hydrogen is released from $\mathrm{Al}_{n} \mathrm{H}_{3 n}$ cluster. As the size of the cluster increases the temperature at which molecular hydrogen is released from the cluster also decreases.

\begin{tabular}{cc}
\hline \hline & $T$ \\
Cluster & $(\mathrm{K})$ \\
\hline $\mathrm{AlH}_{3}$ & 2100 \\
$\mathrm{Al}_{2} \mathrm{H}_{6}$ & 1900 \\
$\mathrm{Al}_{3} \mathrm{H}_{9}$ & 1700 \\
$\mathrm{Al}_{4} \mathrm{H}_{12}$ & 1400 \\
$\mathrm{Al}_{5} \mathrm{H}_{15}$ & 1200 \\
\hline \hline
\end{tabular}

most important thing to note here is the decrease in fragmentation/desorption temperature with increase in the size of clusters.

In all the simulation runs, a heating rate of 0.00025 $\mathrm{K} /$ iteration was used because at a heating rate of 0.0025 $\mathrm{K}$ /iteration molecular $\mathrm{AlH}_{3}$ (alane) remained intact throughout the heating range. There are a number of factors that contribute to the temperature at which molecular hydrogen is desorbed from the cluster. First, the length of equilibration. For instance, molecular hydrogen was only desorbed from $\mathrm{Al}_{3} \mathrm{H}_{9}$ after equilibrating at this temperature $(1700 \mathrm{~K})$ for 3500 ps $(3.5 \mathrm{~ns})$. When the cluster was heated up from 1 to $2000 \mathrm{~K}$ at a rate of $0.00025 \mathrm{~K}$ /iteration, it fragmented into $\mathrm{AlH}_{3}$ and $\mathrm{Al}_{2} \mathrm{H}_{6}$ without molecular hydrogen being desorbed. Second, as mentioned in the foregoing, during the heating process these clusters fragment into smaller clusters (which reagglomerate) prior to desorption of molecular hydrogen. This fragmentation and reagglomeration process occurs throughout the heating range, once the temperature of the cluster has been elevated (roughly at temperatures greater than $700 \mathrm{~K}$, in the timescale of our simulation). We term this phenomenon as dynamic fragmentation-agglomeration. The reason for fragmentation is that at elevated temperatures the system is already at the threshold where it can fragment into smaller clusters. However, the fragments are less stable. As a result they again agglomerate so as to attain greater stability. The agglomeration process is exothermic and is therefore accompanied by a local rise in temperature. This local rise in temperature facilitates the dissociation of $\mathrm{Al}-\mathrm{H}$ bonds resulting in the desorption of molecular hydrogen. The calculated energy costs for fragmentation of $\mathrm{Al}_{4} \mathrm{H}_{12}$ into smaller clusters are summarized in Table XI. During the heating process $\mathrm{Al}_{4} \mathrm{H}_{12}$ fragmented into smaller clusters as follows: First, it fragmented into $\mathrm{Al}_{3} \mathrm{H}_{9}+\mathrm{AlH}_{3}$. This was then followed by reagglomeration back to $\mathrm{Al}_{4} \mathrm{H}_{12}$. The reagglomerated $\mathrm{Al}_{4} \mathrm{H}_{12}$

TABLE XI. The heat of fragmentation of $\mathrm{Al}_{4} \mathrm{H}_{12}$ into various clusters during thermal heating of the cluster. The DFT values were computed using VASP at the PW91 level of theory. The energies are in $\mathrm{kcal} / \mathrm{mol}$.

\begin{tabular}{lcc}
\hline \hline Starting products & DFT(PW91) & REAXFF \\
\hline $\mathrm{Al}_{4} \mathrm{H}_{12} \rightarrow \mathrm{Al}_{4} \mathrm{H}_{10}+\mathrm{H}_{2}$ & 20.92 & 18.77 \\
$\mathrm{Al}_{3} \mathrm{H}_{9}+\mathrm{AlH}_{3}$ & 21.16 & 29.15 \\
$\mathrm{Al}_{2} \mathrm{H}_{6}+\mathrm{Al}_{2} \mathrm{H}_{4}+\mathrm{H}_{2}$ & 28.82 & 32.61 \\
$\mathrm{Al}_{2} \mathrm{H}_{4}+2 \mathrm{AlH}_{3}+\mathrm{H}_{2}$ & 67.75 & 66.93 \\
\hline \hline
\end{tabular}

then refragmented into $\mathrm{Al}_{3} \mathrm{H}_{9}+\mathrm{AlH}_{3}$. This was then followed by reagglomeration and a further fragmentation into $\mathrm{Al}_{2} \mathrm{H}_{6}$, $\mathrm{Al}_{2} \mathrm{H}_{4}$, and $\mathrm{H}_{2}$.

As shown in Table $\mathrm{XI}, \mathrm{Al}_{4} \mathrm{H}_{12}$ can fragment into $\mathrm{Al}_{3} \mathrm{H}_{9}$ and $\mathrm{AlH}_{3}$ at an energy cost of $21.16 \mathrm{kcal} / \mathrm{mol}$ (DFT). This is quite close to the dissociation reaction $\mathrm{Al}_{4} \mathrm{H}_{12} \rightarrow \mathrm{Al}_{4} \mathrm{H}_{10}$ $+\mathrm{H}_{2}$, which costs $20.92 \mathrm{kcal} / \mathrm{mol}$. This shows that it is possible that during the heating up process a given cluster of $\left(\mathrm{Al}_{n} \mathrm{H}_{3 n}\right)$ can fragment into smaller clusters prior to desorption of molecular hydrogen once the temperature required to facilitate fragmentation has been reached.

The DFT calculated activation barrier of $\mathrm{AlH}_{3}$ fragmentation (i.e., $\mathrm{AlH}_{3} \rightarrow \mathrm{Al}+\mathrm{H}_{2}$ ) in the gas phase is $96.94 \mathrm{kcal} /$ mol and that for $\mathrm{Al}_{2} \mathrm{H}_{6}$ decomposition (i.e., $\mathrm{Al}_{2} \mathrm{H}_{6} \rightarrow \mathrm{Al}_{2} \mathrm{H}_{4}$ $\left.+\mathrm{H}_{2}\right)$ is $51 \mathrm{kcal} / \mathrm{mol}$. By comparison the experimental activation energy for hydrogen desorption in $\alpha-\mathrm{AlH}_{3}$ is 23.22 $\mathrm{kcal} / \mathrm{mol} \mathrm{H}_{2}{ }^{41}$ The activation energy barrier for fragmentation of alane is almost four times that for desorption of molecular hydrogen from bulk $\mathrm{AlH}_{3}$. This large difference cannot be due to computational inaccuracies. This implies that the fragmentation temperature of alane is much higher than the temperature of desorption of hydrogen from bulk $\mathrm{AlH}_{3}$. For instance, in the timescale of our simulation, we find that molecular hydrogen dissociates from $\mathrm{Al}_{2} \mathrm{H}_{6}$ at about $1900 \mathrm{~K}$. For bulk $\mathrm{AlH}_{3}$, in the timescale of our simulation, molecular hydrogen desorbs at $700 \mathrm{~K}$. This is clearly much less than the dissociation temperature of alane. From this comparison, it is clear that alane dissociates at a relatively higher temperature in comparison to bigger clusters. It follows therefore that if alanes were to be the facilitators of mass transport of aluminum atoms during the thermal decomposition of $\mathrm{NaAlH}_{4}$ (as suggested in Refs. 20 and 21), there must be a different mechanism by which they can release molecular hydrogen at lower temperature. One mechanism is that alanes undergo oligomerization. We discuss this issue in Sec. III A.

\section{A. Gas phase behavior of alanes}

Figure 6(a) shows the dimerization of two $\mathrm{AlH}_{3}$ molecules, while Fig. 6(b) shows the agglomeration of two $\mathrm{Al}_{2} \mathrm{H}_{6}$ molecules resulting in the formation of a doubly bridged $\mathrm{Al}_{4} \mathrm{H}_{12}$ molecule. The NVT (constant number of particles, constant volume, and constant temperature) simulation was done at $300 \mathrm{~K}$ using Berendsen thermostat ${ }^{42}$ for $30 \mathrm{ps}$. The molecules were placed in a cube of side of $20 \AA$. The dimerization of $\mathrm{AlH}_{3}$ molecules is in agreement with the well known fact that as the size of $\mathrm{AlH}_{3}$ clusters increases so does its stability with respect to the individual $\mathrm{AlH}_{3}$ species. Higher alanes can be easily formed from smaller alanes since the agglomerated alanes are more stable than the individual alane species. ${ }^{35}$ The theoretical formation energies of $\mathrm{Al}_{2} \mathrm{H}_{6}$ molecule from two alane molecules as computed by DFT and REAXFF are $-19.47 \mathrm{kcal} / \mathrm{mol} \mathrm{AlH}_{3}$ and $-18.2 \mathrm{kcal} / \mathrm{mol}$ $\mathrm{AlH}_{3}$, respectively. The DFT value is consistent with the previous works in Refs. 43-46. From Fig. 6(a), the dimerization energy for alanes is approximately $-19 \mathrm{kcal} / \mathrm{mol}$ per $\mathrm{AlH}_{3}$. This is consistent with the calculated value in Table XII, which shows the energy of agglomeration of various small clusters of $\mathrm{Al}_{n} \mathrm{H}_{3 n}$ series as calculated using DFT and 

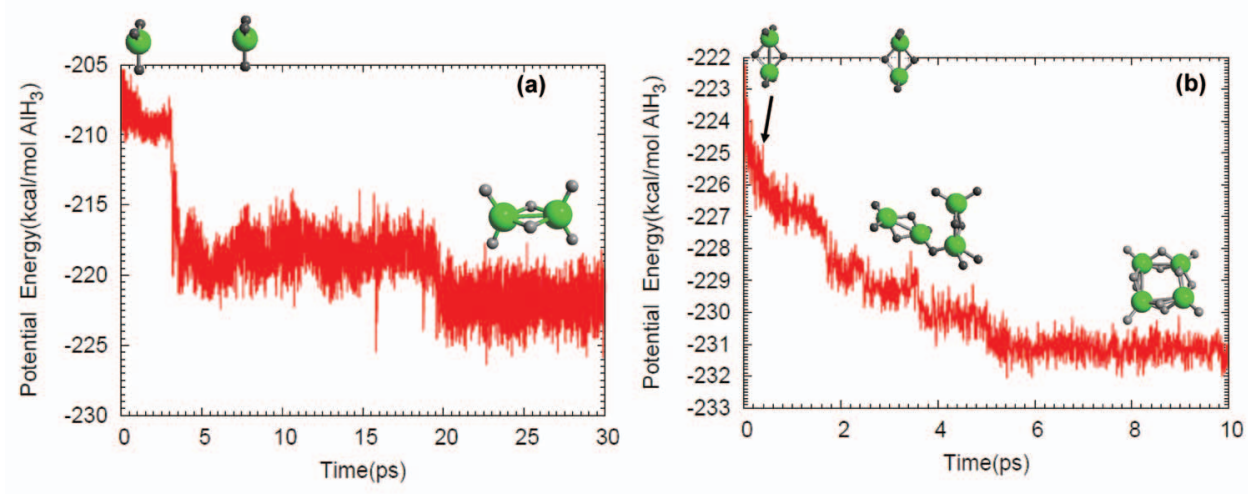

FIG. 6. Illustrations of the atomic configurations and energy profiles for (a) alane dimerization reaction and (b) agglomeration of $\mathrm{Al}_{2} \mathrm{H}_{6}$ molecules.
REAXFF.

To study the correlation between agglomeration and desorption of molecular hydrogen, we did a MD simulation using $20 \mathrm{Al}_{2} \mathrm{H}_{6}$ molecules. We used $\mathrm{Al}_{2} \mathrm{H}_{6}$ molecules because $\mathrm{Al}_{2} \mathrm{H}_{6}$ molecule is more stable relative to two alanes $\left(\mathrm{AlH}_{3}\right.$ molecules $)$. The molecules were placed at least $10 \AA$ apart in a cubic box of side of $80 \AA$. The system was first minimized to find the nearest metastable state. After minimization, the system's temperature was ramped up to $1000 \mathrm{~K}$. This was then followed by a NVT MD equilibration period, using Berendsen thermostat. The temperature of $1000 \mathrm{~K}$ was chosen because we wanted to observe the desorption of molecular hydrogen during the agglomeration process. As will be shown later, even in the temperature range of 300-800 K agglomeration still takes place but molecular hydrogen is not desorbed. In the equilibration process, at $0 \mathrm{ps}$, the following molecules/clusters exists in the system: $\mathrm{Al}_{8} \mathrm{H}_{24}$, two $\mathrm{Al}_{6} \mathrm{H}_{18}$, two $\mathrm{Al}_{4} \mathrm{H}_{12}$, and six $\mathrm{Al}_{2} \mathrm{H}_{6}$. This is so because during the minimization and temperature ramping up process some of the $\mathrm{Al}_{2} \mathrm{H}_{6}$ molecules agglomerated. As illustrated in Fig. 7, at the end of the simulation there are two molecular hydrogens desorbed from the agglomerated cluster.

A number of factors contribute to desorption of molecular hydrogen. First, the agglomeration process is exothermic. Although, globally, the temperature is kept constant by a thermostat, there is a local rise in temperature due to exothermic nature of the agglomeration process. This local rise in temperature facilitates the instantaneous dissociation of the Al-H bond. Therefore, it becomes easy to desorb molecular hydrogen at this temperature $(1000 \mathrm{~K})$. Second, the growth of the cluster leads to the existence of many surface atoms, which are weakly bonded to aluminum atoms. Bigger clusters provide more facile paths for hydrogen desorption as they can make $\mathrm{Al}-\mathrm{Al}$ metal bonds to compensate for the loss of $\mathrm{Al}-\mathrm{H}$ bonds. Although the local rise in temperature during

TABLE XII. The energy of agglomeration (per $\mathrm{AlH}_{3}$ ) of various small clusters of the $\mathrm{Al}_{n} \mathrm{H}_{3 n}$ series as calculated using DFT and REAXFF.

\begin{tabular}{lcc}
\hline \hline Cluster & DFT & REAXFF \\
\hline $2 \mathrm{AlH}_{3} \rightarrow \mathrm{Al}_{2} \mathrm{H}_{6}$ & -19.47 & -18.17 \\
$3 \mathrm{AlH}_{3} \rightarrow \mathrm{Al}_{3} \mathrm{H}_{9}$ & -20.86 & -22.46 \\
$4 \mathrm{AlH}_{3} \rightarrow \mathrm{Al}_{4} \mathrm{H}_{12}$ & -20.94 & -23.88 \\
$5 \mathrm{AlH}_{3} \rightarrow \mathrm{Al}_{5} \mathrm{H}_{15}$ & -22.19 & -24.74 \\
$6 \mathrm{AlH}_{3} \rightarrow \mathrm{Al}_{6} \mathrm{H}_{18}$ & -20.90 & -25.27 \\
\hline \hline
\end{tabular}

the agglomeration process might play a role in hydrogen desorption, in the long term limit, large cluster size effect is the major contributor to desorption of molecular hydrogen.

In Fig. 7 the snapshot at 0 ps shows the initial clusters after being heated up to $1000 \mathrm{~K}$. Already at this stage some $\mathrm{A}_{2} \mathrm{H}_{6}$ molecules have agglomerated. Notice the ringlike conformation of $\mathrm{Al}_{6} \mathrm{H}_{18}$ in Fig. 7. At 260.9375 ps the cluster present in the system is $\mathrm{Al}_{40} \mathrm{H}_{120}$, implying that all the small clusters have agglomerated into one cluster. At 261 ps the cluster undergoes partial fragmentation leading to the formation of $\mathrm{Al}_{39} \mathrm{H}_{117}$ and $\mathrm{AlH}_{3}$. This partial fragmentation and reagglomeration goes back and forth throughout the simulation period. The first molecular hydrogen is desorbed at $267.875 \mathrm{ps}$, leading to the formation of the following clusters/molecules: $\mathrm{Al}_{39} \mathrm{H}_{114}, \mathrm{AlH}_{4}$, and $\mathrm{H}_{2}$. Actually, the $\mathrm{AlH}_{4}$ moiety is quite unstable and is immediately reabsorbed back by the bigger cluster. At 286.25 ps we have the following clusters/molecules: $\mathrm{Al}_{7} \mathrm{H}_{23}, \mathrm{Al}_{33} \mathrm{H}_{95}$, and $\mathrm{H}_{2}$. At the end of the simulation (1000 ps) the clusters/molecules present in the system are $\mathrm{Al}_{40} \mathrm{H}_{116}$ and two molecular hydrogen. What is quite interesting is that in the end structure (at $1000 \mathrm{ps)}$ there is a central aluminum atom which has six neighboring hydrogen atoms. This is illustrated in Fig. 7(b). The central aluminum atom is in a pentagonal ring of aluminum atoms, which resembles the coordination of aluminum in $\beta-\mathrm{AlH}_{3}$.

In a different simulation run, in which the temperature of the system was kept fixed at $800 \mathrm{~K}$, the $\mathrm{Al}_{2} \mathrm{H}_{6}$ molecules agglomerated into $\mathrm{Al}_{40} \mathrm{H}_{120}$ cluster during the 500 ps simulation run. However, at this temperature no molecular hydrogen was desorbed. Further tests (simulations) showed that in the temperature range of $300-800 \mathrm{~K}$ the $\mathrm{Al}_{2} \mathrm{H}_{6}$ clusters agglomerated into one cluster $\left(\mathrm{Al}_{40} \mathrm{H}_{120}\right)$. However, in these cases no molecular hydrogen was desorbed from the cluster. Figure 8(a) shows the agglomerated structure while the pair distribution function for the annealed (to $0 \mathrm{~K}$ ) agglomerated cluster is illustrated in Fig. 8(b). The figure shows that the radial distribution function has a slightly broad delta peaks. This suggests that the cluster is in a quasicrystalline state. The quasicrystalline state can be explained by the fact that the aluminum and hydrogen atoms are somehow arranged in a semiperiodic pattern. The average $\mathrm{Al}-\mathrm{Al}$ distance is approximately $3.0 \AA$. This value compares quite well to the DFT calculated Al-Al bond length in $\beta-\mathrm{AlH}_{3}(3.2 \AA)$. However, this structure does not have the local coordination of any of the condensed phases of $\mathrm{AlH}_{3}$. There are some central 
O ps

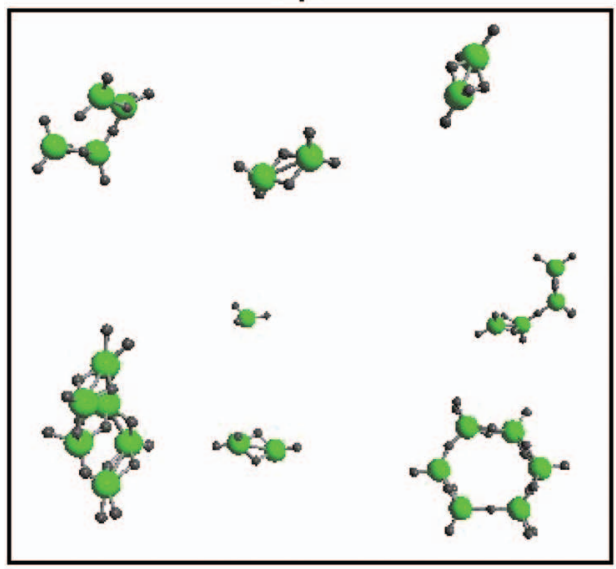

$\mathrm{Al}_{8} \mathrm{H}_{24}, 2 \times \mathrm{Al}_{6} \mathrm{H}_{18}, 6 \times \mathrm{Al}_{2} \mathrm{H}_{6}, 2 \times \mathrm{Al}_{4} \mathrm{H}_{12}$
1000 ps

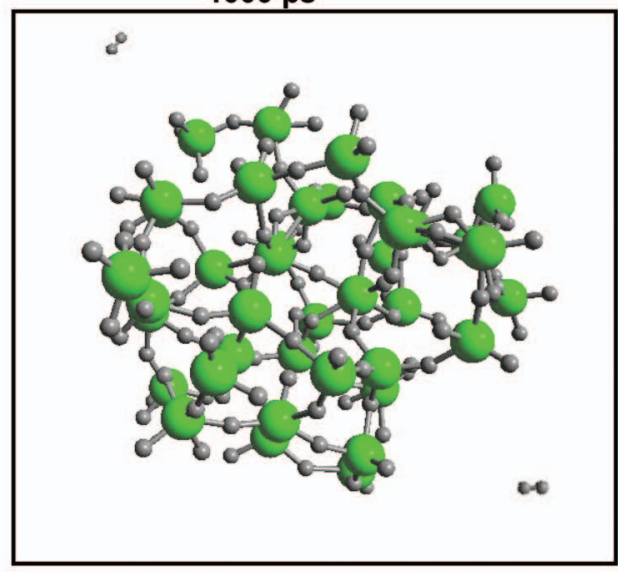

$\mathrm{Al}_{40} \mathrm{H}_{116}, 2 \times \mathrm{H}_{2}$
FIG. 7. Snapshots of the $\mathrm{Al}_{2} \mathrm{H}_{6}$ clusters at the (a) beginning and (b) end of the simulation.
$\mathrm{Al}$ atoms that are five coordinated in hydrogen, while the rest have four hydrogen neighbors. The changes in charge redistribution as a result of agglomeration (i.e., plots of the clusters at the beginning of the simulation and that of the agglomerated cluster at the end of the simulation run) are shown in Fig. 9. The figure shows that at the end of the simulation run $(500 \mathrm{ps})$, there is an upward shift on the charge on aluminum atoms as compared to at the beginning of the simulation. Therefore there is a substantial charge transfer from aluminum atoms to hydrogen atoms during the agglomeration process. The distribution of charge on aluminum atoms is also less than the nominal charge of aluminum, implying that the bonding between $\mathrm{Al}$ and hydrogen is covalent. Although there is an increase in the negative charge on hydrogen atoms a considerable number still have charges in the range -0.1 to -0.5 . These are the surface hydrogen atoms as can be seen in Fig. 8 .

\section{ABSTRACTION OF MOLECULAR HYDROGEN}

An important question in hydrogen storage is knowing the nature of structural transformation that takes place during the desorption process of hydrogen. In order to get a better insight of structural transformation during the desorption of hydrogen, we simulated successive abstraction of surface molecular hydrogen from a representative aluminum hydride nanoparticle $\left(\mathrm{Al}_{28} \mathrm{H}_{84}\right.$ cluster). This is illustrated in Fig. 10. The abstraction process of surface molecular hydrogen is given by:

$$
\mathrm{Al}_{28} \mathrm{H}_{n} \rightarrow \mathrm{Al}_{28} \mathrm{H}_{n-2}+\mathrm{H}_{2},
$$

where $n=84-0$. The desorption energy is defined as

$$
E^{\text {desorb }}=\left[E_{\mathrm{Al}_{28} \mathrm{H}_{84-n}}+E_{n / 2 \mathrm{H}_{2}}\right]-E_{\mathrm{Al}_{28} \mathrm{H}_{84}},
$$

where $n=2,4,6,8, \ldots, 48,50,52, \ldots, 84$.

Systematically, in the abstraction process, clusters were first minimized and then annealed to $0 \mathrm{~K}$ using MD simulation to find the nearest metastable conformation. After minimization, the temperature was ramped up to between 600 and $900 \mathrm{~K}$ at a rate of $0.025 \mathrm{~K}$ /iteration. This was then followed by a NVT (constant number of particles, constant volume, and constant temperature) equilibration period of 300000 steps at this temperature (600-900 K) using Berendsen thermostat. ${ }^{42}$ In all cases, a time step of $0.25 \mathrm{fs}$ was used. After the equilibration run, the clusters were annealed to $0 \mathrm{~K}$ at a rate of $0.0025 \mathrm{~K}$ /iteration. After this, molecular hydrogen was abstracted by removing two hydrogen atoms from the configuration at $0 \mathrm{~K}$. This was done iteratively until all the hydrogen atoms were abstracted. The entire process was repeated several times, each time starting out with $\mathrm{Al}_{28} \mathrm{H}_{84}$ but with a different geometrical arrangement.

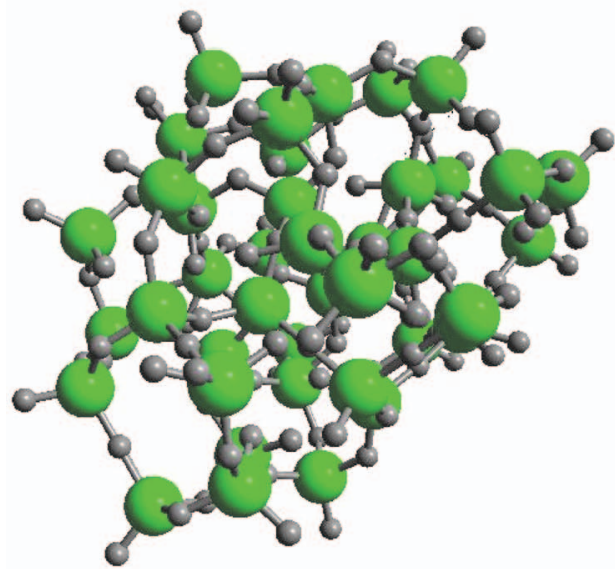

(a)

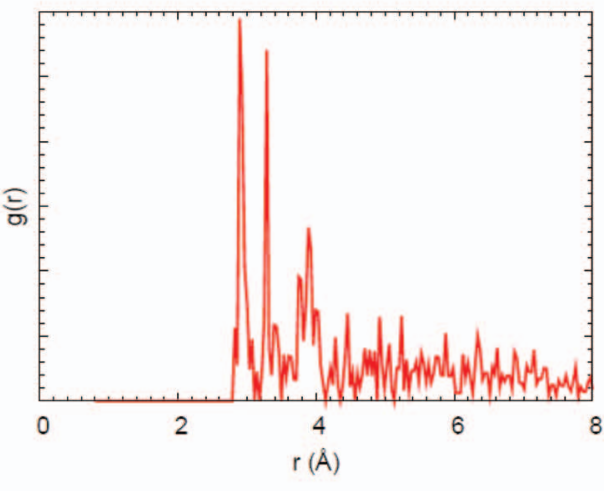

(b)
FIG. 8. (a) The completely agglomerated $\mathrm{Al}_{2} \mathrm{H}_{6}$ clusters at a temperature of $800 \mathrm{~K}$. No molecular hydrogen was desorbed at this temperature. (b) The $\mathrm{Al}-\mathrm{Al}$ pair distribution function of the cooled agglomerated $\mathrm{Al}_{2} \mathrm{H}_{6}$ clusters. The agglomerate was annealed to $0 \mathrm{~K}$ at a rate of $0.0025 \mathrm{~K} /$ iteration. 
Only the energies of the most stable conformations that gave rise to the nearly smooth curve shown in Fig. 10 were considered.

Figure 10 shows the trend in particle stability as a function of hydrogen unloading. The negative values of the heat of formation show that at the initial stages the forward decomposition reaction in Eq. (4) is thermodynamically favored. During the abstraction process, the exothermicity of the desorption process decreases with increasing abstraction of molecular hydrogen. When almost a half of the hydrogen atoms have been abstracted, the process becomes endothermic.

The observation can be understood as follows. Region (I) shows the high rate segment when desorption of molecular hydrogen is very favorable, while region (II) is the slow rate segment when desorption of molecular hydrogen systematically becomes unfavorable. The cluster size dependence of the desorption process is related to the local coordination of aluminum atoms with hydrogen. Therefore, the higher the concentration of hydrogen the more favored the decomposition of $\mathrm{AlH}_{3}$. Large aluminum clusters can be understood to have a bulklike decomposition as follows:

$$
\left(\mathrm{AlH}_{3}\right)_{2} \rightarrow(\mathrm{AlH})\left(\mathrm{AlH}_{3}\right)+\mathrm{H}_{2} .
$$

The reaction in Eq. (6) should be interpreted as follows. The $\mathrm{AlH}_{3}$ unit from which the hydrogen is abstracted is embedded in other $\mathrm{AlH}_{3}$ units. There is a saturation of $\mathrm{AlH}_{3}$ species in the cluster such that each $\mathrm{AlH}_{3}$ species is surrounded by other $\mathrm{AlH}_{3}$ species. This provides facile paths for hydrogen desorption as they can make $\mathrm{Al}-\mathrm{Al}$ metal bonds to compensate for the loss of $\mathrm{H}-\mathrm{Al}$ bonds. The critical point in Fig. 10 is the point at which there is a transition from exothermicity to endothermicity. In other words, the abstraction of hydrogen starts to become unfavorable since the system is stabilized. We can understand the stable region as follows. There are fewer hydrogen atoms in comparison to aluminum atoms. This implies that the $\mathrm{AlH}_{3}$ units are dispersed within the system and not embedded in other $\mathrm{AlH}_{3}$ units. Therefore, the abstraction process essentially behaves like dissociation of $\mathrm{AlH}_{3}, \mathrm{AlH}_{3} \rightarrow \mathrm{AlH}+\mathrm{H}_{2}$, which is energetically unfavorable.

Intuitively, one is bound to think that as more and more surface hydrogen atoms are abstracted, the remaining hydrogen atoms should become subsurface and be strongly bound to the aluminum atoms (see Ref. 17). However, this is not the case. As more and more surface hydrogen atoms are abstracted the bulk hydrogen atoms come to the surface. In fact, for $\mathrm{Al}_{28} \mathrm{H}_{84}$ the bulk aluminum atoms are octahedrally coordinated to hydrogen atoms (the average bond lengths are $d_{\mathrm{Al}-\mathrm{H}}=1.64 \AA$ and $d_{\mathrm{Al}-\mathrm{Al}}=3.342 \AA$ ), while for $\mathrm{Al}_{28} \mathrm{H}_{42}$ the bulk aluminum atoms are tetrahedrally coordinated to hydrogen atoms (average bond lengths are $d_{\mathrm{Al}-\mathrm{H}}=1.65 \AA$ and $d_{\mathrm{Al}-\mathrm{Al}}=2.843 \AA$ ). In the case of $\mathrm{Al}_{28} \mathrm{H}_{4}$ the bulk aluminum atoms have no nearest hydrogen neighbors, instead they are icosahedrally coordinated to neighboring aluminum atoms. The average $\mathrm{Al}-\mathrm{Al}$ bond length in this case is $2.75 \AA$. Notice that $d_{\mathrm{Al}-\mathrm{H}}$ remains almost constant throughout the abstraction process, whereas $d_{\mathrm{Al}-\mathrm{Al}}$ decreases toward the aluminum bulk value. The decrease in $d_{\mathrm{Al}-\mathrm{Al}}$ with increasing abstraction of molecular hydrogen implies that there is a transition toward

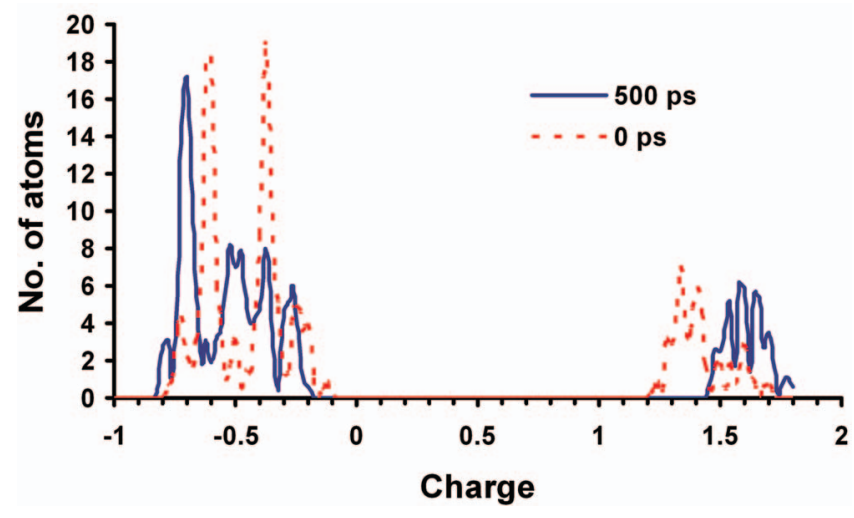

FIG. 9. The charge distribution plots of the alane clusters $(0 \mathrm{ps})$ at the beginning of the simulation and $(500 \mathrm{ps})$ that of the agglomerated cluster at the end of the simulation run.

metallization. On the other hand, the almost constant value of $d_{\mathrm{Al}-\mathrm{H}}$ shows that the $\mathrm{Al}-\mathrm{H}$ bond length is independent of the chemical environment for a given system (in this case binary aluminum hydride). The observations detailed herein show that aluminum atoms prefer to form bond with each other rather than with hydrogen. Hydrogen atoms prefer to stay on the surface rather than subsurface sites and since the surface hydrogen atoms prefer to mostly occupy the less stable twofold (bridge) sites, it becomes easy to desorb them. On the $\mathrm{Al}(111)$ surface hydrogen prefers to occupy the threecoordinated hollow (fcc and hcp) sites. The fact that hydrogen atoms prefer to occupy the bridge sites in clusters of this size shows that the surface has a corrugated morphology. The behavior of aluminum hydride cluster is therefore very different from that of $\mathrm{NaH}^{17}$ It is also markedly different from that of $\mathrm{MgH}_{2}$. Wagemans ${ }^{47}$ showed that the hydrogen atoms in hydrogen depleted magnesium hydride prefer to cluster together instead of being evenly distributed. Using REAXFF, Cheung et al. ${ }^{18}$ showed that there are no surface hydrogen atoms for hydrogen depleted $\mathrm{Mg}_{20} \mathrm{H}_{x}(x=2,4,6)$ systems.

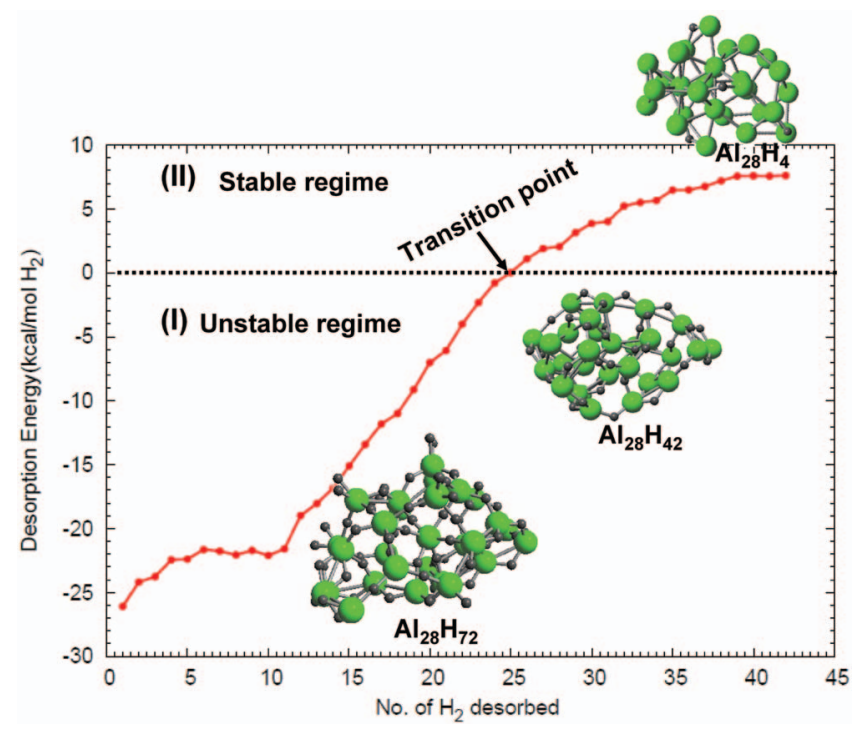

FIG. 10. Desorption energy $E^{\text {desorb }}$ as a function of number of $\mathrm{H}_{2}$ molecules abstracted from the system. The reference energy, shown by the dotted line, is the energy for $\mathrm{Al}_{28} \mathrm{H}_{84}$. 

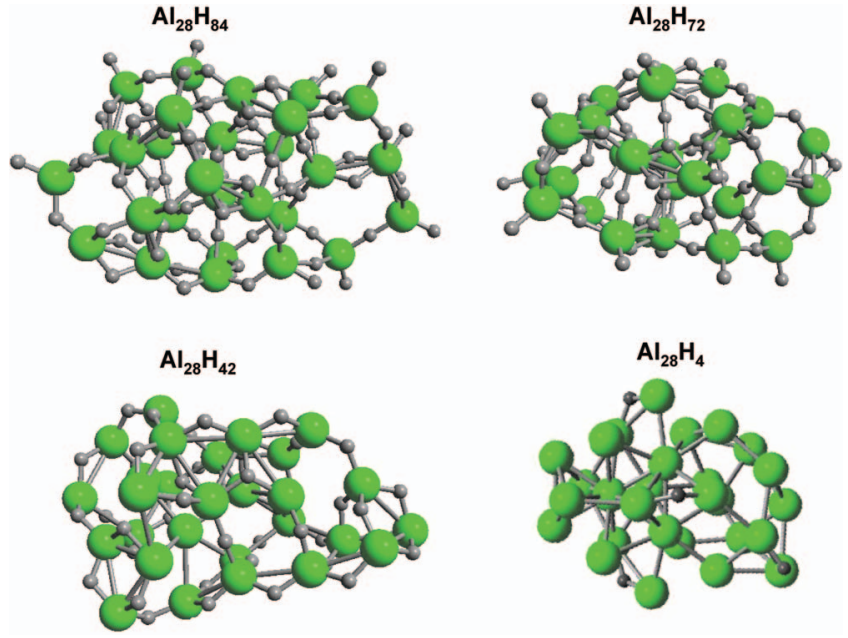

FIG. 11. Geometries of the annealed clusters of $\mathrm{Al}_{28} \mathrm{H}_{84}, \mathrm{Al}_{28} \mathrm{H}_{72}, \mathrm{Al}_{28} \mathrm{H}_{42}$, and $\mathrm{Al}_{28} \mathrm{H}_{4}$. In the hydrogen deficient $\mathrm{Al}_{28} \mathrm{H}_{4}$ cluster the hydrogen atoms prefer to occupy surface sites rather than bulk.

We find a different behavior for hydrogen atoms in aluminum hydride systems. In a hydrogen depleted aluminum hydride cluster, the hydrogen atoms are randomly scattered over the aluminum rich surface. This can be seen in Fig. 11, which shows the geometries of the annealed clusters of $\mathrm{Al}_{28} \mathrm{H}_{84}, \mathrm{Al}_{28} \mathrm{H}_{72}, \mathrm{Al}_{28} \mathrm{H}_{42}$, and $\mathrm{Al}_{28} \mathrm{H}_{4}$.

The dynamics taking place within the structure during the systematic abstraction of molecular hydrogen can be understood better by examining charge transfer. To investigate the changes in charge transfer due depletion of hydrogen atom, charge distribution plots were made for $\mathrm{Al}_{28} \mathrm{H}_{84}$, $\mathrm{Al}_{28} \mathrm{H}_{42}$, and $\mathrm{Al}_{28} \mathrm{H}_{4}$ clusters during the abstraction runs. This is illustrated in Fig. 12. As shown in Fig. 12, in $\mathrm{Al}_{28} \mathrm{H}_{84}$ there is a broad distribution of charges on both aluminum and hydrogen. This is because there are many subsurface and surface hydrogen atoms. The low charges are associated with surface atoms, which have less number of neighbors. As one moves from $\mathrm{Al}_{28} \mathrm{H}_{84}$ to $\mathrm{Al}_{28} \mathrm{H}_{4}$ the distribution of charges of aluminum atoms tends toward the lower numbers, and concomitantly there is an increase in the negative charge on hydrogen atoms. This is reflected in the charge distribution on $\mathrm{Al}_{28} \mathrm{H}_{42}$ as illustrated in Fig. 12. However, we see in Fig. 12 that the charges located at the hydrogen atoms in $\mathrm{Al}_{28} \mathrm{H}_{4}$ actually decrease. We can understand this disparity as fol- lows. Since charge distribution is a function of the number of nearest neighbors, this shows that with increasing abstraction of hydrogen there is a decrease in the number of nearest neighbors of opposite charge for both aluminum and hydrogen. The four hydrogen atoms are not subsurface but rather occupy surface sites where they are lowly coordinated to aluminum neighbors. Therefore, they have less number of aluminum atom neighbors. This makes them to have low negative charges. In the case of aluminum, at this point the aluminum atoms have formed metallic bonds since the number of hydrogen in the system is negligible. In other words the system tends toward metallization. In $\mathrm{Al}_{28} \mathrm{H}_{4}$ there are three aluminum atoms that have icosahedral coordination. These aluminum atoms, therefore, have a bulk coordination. This suggests that once almost half the hydrogen atoms have been removed the hydrogen deficient aluminum hydride tends toward metallization.

\section{MOLECULAR HYDROGEN TRAPPED IN ALUMINUM HYDRIDE SOLID}

For many years now, there have been discussions on the possibility of molecular hydrogen being trapped in the channels of potential hydrogen storage materials such as $\mathrm{NaAlH}_{4}$ and $\mathrm{AlH}_{3}{ }^{48-51}$ The issue of hydrogen molecules being trapped in cages or channels of hydrogen storage media will present the next technological challenges with a view to fully harnessing the storage capabilities of these systems. Trapped molecular hydrogen implies that not all the desorbed hydrogen diffuses out during the thermal decomposition process of the potential hydrogen storage materials. This reduces the efficiency of these materials. How to channel out these trapped hydrogen molecules from the system during the desorption process is clearly a nontrivial task. Using nuclear magnetic resonance (NMR) spectra, Herberg et al. deduced that there were molecular hydrogen trapped in small cages in the interstitial sites of $\mathrm{NaAlH}_{4} \cdot{ }^{52}$ Recent experimental work, using proton NMR, by Senadheera et al. showed that molecular hydrogen can be trapped in solid matrix of $\mathrm{AlH}_{3}$ during the thermal decomposition of $\mathrm{AlH}_{3} .{ }^{53}$ To simulate this possibility a cluster of $\mathrm{AlH}_{3}$, consisting of 472 atoms, was heated up. The cluster was built up from a supercell of $\beta-\mathrm{AlH}_{3}$ by removing the periodic boundary conditions. $\beta-\mathrm{AlH}_{3}$ has very open channels compared to the $\alpha$-phase.

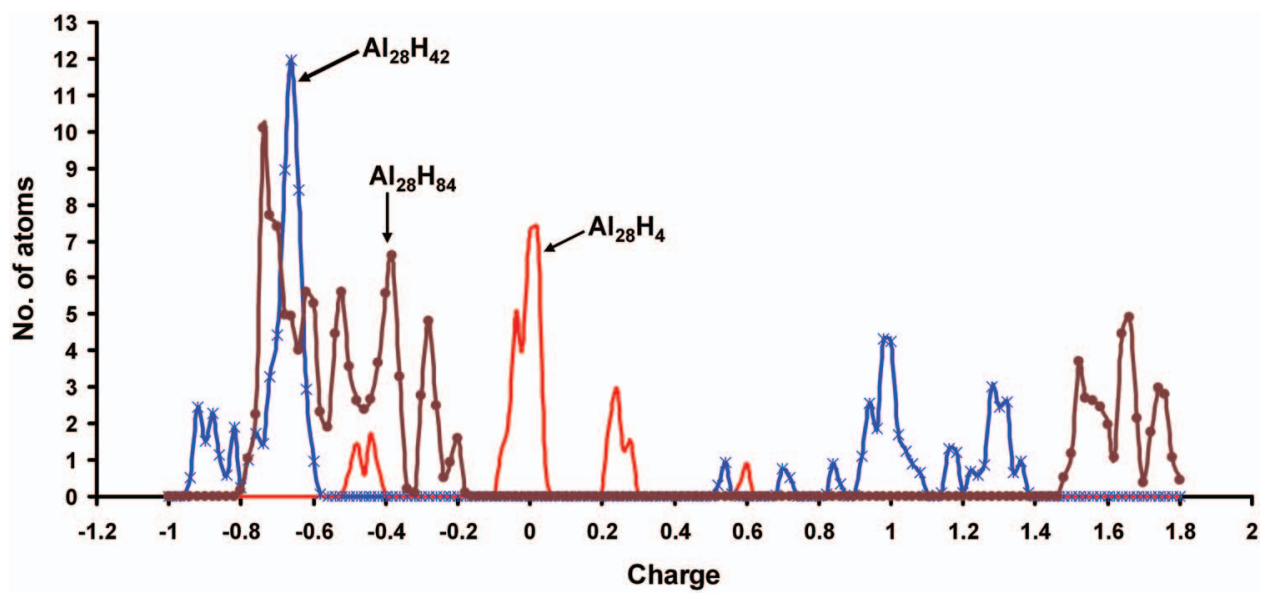

FIG. 12. Charge distribution plots showing the transfer of charge during abstraction process of molecular hydrogen from $\mathrm{Al}_{28} \mathrm{H}_{84}$ cluster. The hydrogen atoms are negatively charged. 


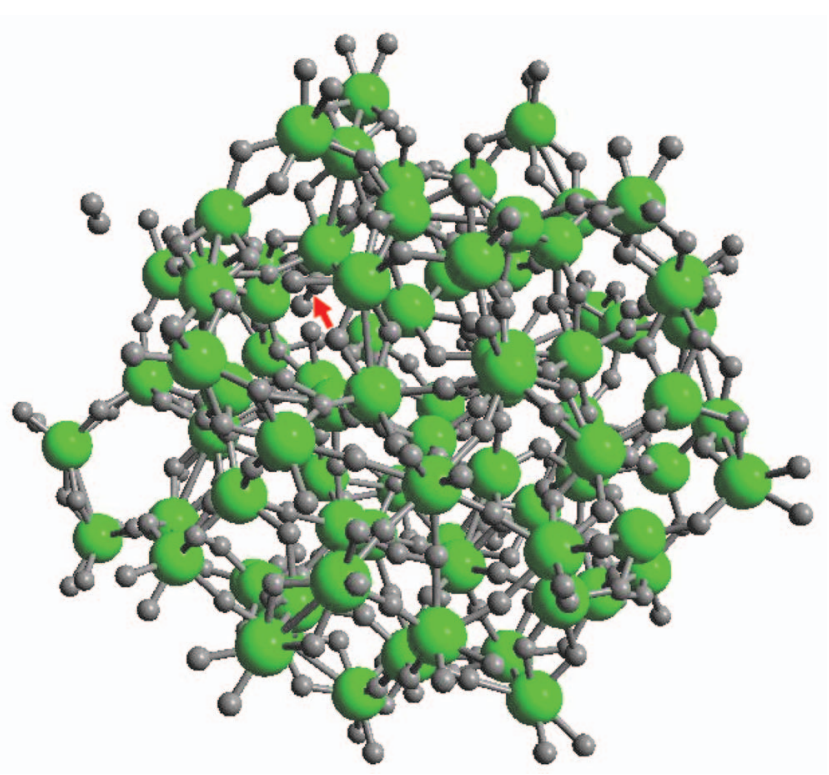

FIG. 13. The arrow shows a hydrogen molecule trapped in $\mathrm{AlH}_{3}$ channel.

The resultant cluster was first minimized then equilibrated at $300 \mathrm{~K}$. The equilibrated cluster was then heated to $800 \mathrm{~K}$, at a heating rate of $0.0025 \mathrm{~K}$ /iteration. This temperature $(800$ K) was maintained for 120 ps. Figure 13 shows a hydrogen molecule, indicated by an arrow, trapped in the channels of the cluster.

There are dispersive van der Waals interactions between the trapped molecule and the walls of the cages. The trapped molecular hydrogen easily diffuses along the channels into different cages of the cluster. It was noticed that after sometime the molecule escaped. At a faster heating rate the molecular hydrogen escaped at a much earlier time due to the collapse of some cages of the cluster. Even at a constant temperature of $500 \mathrm{~K}$, the molecular hydrogen escaped after sometime although at this temperature it took much longer time to escape.

These results therefore presents an unambiguous identification that molecular hydrogen can be trapped in $\mathrm{AlH}_{3}$ matrix and for that matter other hydrogen storage materials. We should re-emphasize that our cluster consisted of only 472 atoms (with an approximate width of $1.6 \mathrm{~nm}$ ). In experiments, usually after ball milling, the size of the particles vary from 150 to $200 \mathrm{~nm}$. Such a particle can contain as much as hundreds of thousands of atoms. This implies that several hundreds or even thousands of molecular hydrogen can be trapped in cages or interstitial sites within such a solid matrix during its thermal decomposition.

\section{CONCLUSION}

Based on DFT derived values for bond dissociation profiles, charge distribution, reaction energy data for small clusters, and EoSs for $\mathrm{Al}$ and $\mathrm{AlH}_{3}$ condensed phases, a reactive force field, $\left(\right.$ REAXFFAlH $H_{3}$ ), has been parametrized for $\mathrm{AlH}_{3}$ systems. REAXFFAlH $\mathrm{H}_{3}$ is built on the same formalism as previous REAXFF descriptions. ${ }^{17,18}$ We find that REAXFFAlH $_{3}$ correctly reproduces there DFT data. For the experimentally stable $\alpha-\mathrm{AlH}_{3}$ phase, REAXFF gives a heat of formation of
-3.1 kcal $/ \mathrm{mol} \mathrm{H}_{2}$, which compares excellently with DFT value of $-2.36 \mathrm{kcal} / \mathrm{mol} \mathrm{H}_{2}$. The experimental heat of formation ranges from $-2.37 \pm 0.1 \mathrm{kcal} / \mathrm{mol} \mathrm{H}_{2}$ (Ref. 2) to $-2.72 \pm 0.2 \mathrm{kcal} / \mathrm{mol} \mathrm{H}_{2}{ }^{8}$.

In the gas phase, there is a thermodynamically driven agglomeration of $\mathrm{AlH}_{3}$ molecules due to the tendency of the system toward attaining a lower free energy configurations. In the initial stages the dominant factor contributing to desorption of hydrogen is the local rise in temperature during the agglomeration process, which weakens/dissociates the $\mathrm{Al}-\mathrm{H}$ bond. However, as the size of the agglomerated cluster increases the large cluster size effect starts to play a decisive role in desorption of hydrogen. The other contributing factor, to a smaller extent, is the intercluster attraction, which weakens the Al-H bond leading to desorption of molecular hydrogen in a nearby cluster as the clusters move toward each other. The presence of defects such as stepped surfaces accelerates the formation of alane oligomers. These simulation results, especially the oligomerization process, are qualitatively consistent with the experimental work of Go et al., ${ }^{54}$ who noted that heating of alanes at $360 \mathrm{~K}$ led to "loss of both mobile and smaller alanes to higher alanes and to desorption." They showed that small alane clusters do agglomerate to form large clusters but added that experimental limitations might hinder the observation of the resultant compound aluminum hydride clusters.

In the abstraction process of molecular hydrogen, it was seen that with increasing abstraction the remaining hydrogen atoms prefer to occupy surface sites rather than subsurface sites. This behavior is quite different from that of $\mathrm{NaH}$ (Ref. 17) and $\mathrm{MgH}_{2}$ (Refs. 18 and 47) clusters in which with increasing abstraction of molecular hydrogen the remaining hydrogen atoms prefer subsurface sites. In the gas phase, there is a thermodynamically driven agglomeration of alane molecules. In the process of agglomeration, molecular hydrogen is desorbed from the oligomer. Using the method of MD, based on REAXFF, we have unambiguously identified a molecular hydrogen trapped in the $\mathrm{AlH}_{3}$ matrix.

\section{ACKNOWLEDGMENTS}

This work was supported by the Advanced Chemical Technologies for Sustainability (ACTS), which is funded by Nederlandse Organisatie voor Wetenschappelijk Onderzoek (NWO). J.G.O.O. acknowledges fruitful discussions with Jason Graetz and Andreas Zuttel.

\footnotetext{
${ }^{1}$ F. M. Brower, N. E. Matzek, P. F. Reigler, H. W. Rinn, C. B. Roberts, D. L. Schmidt, J. A. Snover, and K. Terada, J. Am. Chem. Soc. 98, 2450 (1976).

${ }^{2}$ J. Graetz and J. J. Reilly, J. Alloys Compd. 424, 262 (2006).

${ }^{3}$ J. W. Turley and H. W. Rinn, Inorg. Chem. 8, 18 (1969).

${ }^{4}$ X. Ke, A. Kuwabara, and I. Tanaka, Phys. Rev. B 71, 184107 (2005).

${ }^{5}$ J. Graetz and J. J. Reilly, J. Phys. Chem. B 109, 22181 (2005).

${ }^{6}$ M. Baranowski and B. Tkacz, Z. Phys. Chem. Neue Folge 135, 27 (1983)

${ }^{7}$ S. K. Konovalov and B. M. Bulychev, Inorg. Chem. 34, 172 (1995).

${ }^{8}$ G. C. Sinke, L. C. Walker, F. L. Oetting, and D. R. Stull, J. Chem. Phys. 47, 2759 (1967).

${ }^{9}$ B. Bogdanović and G. Sandrock, MRS Bull. 27, 712 (2002).

${ }^{10}$ G. Sandrock, J. Reilly, J. Graetz, W.-M. Zhou, J. Johnson, and J. Wegrzyn, Appl. Phys. A: Mater. Sci. Process. 80, 687 (2005).

${ }^{11}$ G. Sandrock, J. Reilly, J. Graetz, W.-M. Zhou, J. Johnson, and J.
} 
Wegrzyn, J. Alloys Compd. 421, 185 (2006).

${ }^{12}$ A. Strachan, A. C. van Duin, D. Chakraborty, S. Dasgupta, and W. A. Goddard, Phys. Rev. Lett. 91, 098301 (2003).

${ }^{13}$ A. C. T. van Duin, A. Strachan, S. Stewman, Q. Zhang, X. Xu, and W. Goddard III, J. Phys. Chem. A 107, 3803 (2003).

${ }^{14}$ Q. Zhang, T. ąan, A. C. T. van Duin, W. A. Goddard, Y. Qi, and L. G. Hector, Phys. Rev. B 69, 045423 (2004).

${ }^{15}$ J. G. O. Ojwang', R. van Santen, G. J. Kramer, A. C. T. van Duin, and W. A. Goddard, J. Chem. Phys. 129, 244506 (2008).

${ }^{16}$ A. C. T. van Duin, S. Dasgupta, F. Lorant, and W. Goddard III, J. Phys. Chem. A 105, 9396 (2001)

${ }^{17}$ J. G. O. Ojwang, R. van Santen, G. J. Kramer, A. C. T. van Duin, and W. A. Goddard, J. Chem. Phys. 128, 164714 (2008).

${ }^{18}$ S. Cheung, W. Deng, A. C. T. van Duin, and W. A. Goddard III, J. Phys. Chem. A 109, 851 (2005).

${ }^{19}$ J. K. Gross, S. Guthrie, S. Takara, and G. Thomas, J. Alloys Compd. 297, 270 (2000).

${ }^{20}$ J. G. O. Ojwang, R. van Santen, G. J. Kramer, and X. Ke, J. Solid State Chem. 181, 3037 (2008).

${ }^{21}$ R. T. Walters and J. H. Scogin, J. Alloys Compd. 379, 135 (2004).

${ }^{22}$ J. Tersoff, Phys. Rev. Lett. 61, 2879 (1988).

${ }^{23}$ D. W. Brenner, Phys. Rev. B 42, 9458 (1990).

${ }^{24}$ W. J. Mortier, S. K. Ghosh, and S. Shankar, J. Am. Chem. Soc. 108, 4315 (1986)

${ }^{25}$ G. Kresse and J. Furthmüller, Phys. Rev. B 54, 11169 (1996).

${ }^{26}$ P. E. Blöchl, Phys. Rev. B 50, 17953 (1994).

${ }^{27}$ J. P. Perdew, J. A. Chevary, S. H. Vosko, K. A. Jackson, M. R. Pederson, D. J. Singh, and C. Fiolhais, Phys. Rev. B 46, 6671 (1992).

${ }^{28}$ J. P. Perdew, K. Burke, and Y. Wang, Phys. Rev. B 54, 16533 (1996).

${ }^{29}$ J. P. Perdew, K. Burke, and M. Ernzerhof, Phys. Rev. Lett. 77, 3865 (1996).

${ }^{30}$ H. J. Monkhorst and J. D. Pack, Phys. Rev. B 13, 5188 (1976).

${ }^{31}$ R. Dovesi, M. Causá, R. Orlando, C. Roetti, and V. R. Saunders, J. Chem. Phys. 92, 7402 (1990).

${ }^{32}$ R. Dovesi, V. R. Saunders, C. Roetti, R. Orlando, C. M. Zicovich-Wilson, F. Pascale, B. Civalleri, K. Doll, N. M. Harrison, I. J. Bush et al., CRYS TAL06 User's Manual (University of Torino, Torino, 2008).
${ }^{33}$ R. Stumpf, Phys. Rev. Lett. 78, 4454 (1997).

${ }^{34}$ H. Hjelmberg, Surf. Sci. 81, 539 (1979).

${ }^{35}$ H. Kawamura, V. Kumar, Q. Sun, and K. Yoshiyuki, Phys. Rev. A 67, 063205 (2003).

${ }^{36}$ C. Wolverton, V. Ozolinš, and M. Asta, Phys. Rev. B 69, 144109 (2004).

${ }^{37}$ H. Grove, M. H. Sørby, H. W. Brinks, and B. C. Hauback, J. Phys. Chem. C 111, 16693 (2007).

${ }^{38}$ J. P. Maehlen, V. A. Yartys, R. V. Denys, M. Fichtner, C. Frommenc, B. M. Bulychev, P. Pattison, H. Emerich, Y. E. Filinchuk, and D. Chernyshov, J. Alloys Compd. 446-447, 280 (2007).

${ }^{39}$ G. Henkelman and H. Jónsson, J. Chem. Phys. 113, 9978 (2000).

${ }^{40}$ G. Henkelman, B. P. Uberuaga, and H. Jónsson, J. Chem. Phys. 113, 9901 (2000).

${ }^{41}$ X. Tang, B. Laube, D. Anton, S.-J. Hwang, and R. Bowman, APS Meeting Abstracts, 2007 (unpublished), p. 39008.

${ }^{42}$ H. J. C. Berendsen, J. P. M. Postma, W. F. van Gunsteren, A. Dinola, and J. R. Haak, J. Chem. Phys. 81, 3684 (1984).

${ }^{43}$ K. Lammertsma and J. Leszczy'nski, J. Phys. Chem. 94, 2806 (1990).

${ }^{44}$ X. Wang, A. Lester, S. Tam, M. E. DeRose, and M. E. Fajardo, J. Am. Chem. Soc. 125, 9218 (2003).

${ }^{45}$ M. Shen and H. F. Schaefer III, J. Chem. Phys. 96, 2868 (1992).

${ }^{46}$ B. K. Rao, P. Jena, S. Burkart, G. Ganteför, and G. Seifert, Phys. Rev. Lett. 86, 692 (2001).

${ }^{47}$ R. W. P. Wagemans, Ph.D. thesis, Universiteit Utrecht, 2006.

${ }^{48}$ G. Majer, E. Stanik, L. E. Valiente Banuet, F. Grinberg, O. Kircher, and M. Fichtner, J. Alloys Compd. 404-406, 738 (2005).

${ }^{49}$ O. J. Zogal, M. Punkkinen, E. E. Ylinen, and B. Stalinski, J. Phys.: Condens. Matter 2, 1941 (1990).

${ }^{50}$ V. P. Tarasov, S. I. Bakum, and S. F. Kuznetsova, Russ. J. Inorg. Chem. 42, 694 (1997).

${ }^{51}$ V. P. Tarasov and G. A. Kirakosyan, Russ. J. Inorg. Chem. 42, 1223 (1997).

${ }^{52}$ J. L. Herberg, R. S. Maxwell, and E. H. Majzoub, J. Alloys Compd. 417, 39 (2006).

${ }^{53}$ L. Senadheera, E. M. Carl, T. M. Ivancic, M. S. Conradi, R. C. Bowman, Jr., S. J. Hwang, and T. J. Udovic, J. Alloys Compd. 463, 1 (2008).

${ }^{54}$ E. Go, K. Thuermer, and J. E. Reutt-Robey, Surf. Sci. 437, 377 (1999). 